\title{
Paying Positive to Go Negative: Advertisers' Competition and Media Reports*
}

\author{
Andrea Blasco $^{\dagger}$, Paolo Pin ${ }^{\ddagger}$,Francesco Sobbrio ${ }^{\S}$
}

July 8, 2011

\begin{abstract}
This paper analyzes a two-sided market for news where advertisers may pay a media outlet to conceal negative information about the quality of their own product (paying positive to avoid negative) and/or to disclose negative information about the quality of their competitors' products (paying positive to go negative). We show that whether advertisers have negative consequences on the accuracy of news reports or not ultimately depends on the extent of correlation among advertisers' products. Specifically, the lower the correlation among the qualities of the advertisers' products, the (weakly) higher the accuracy of the media outlet' reports. Moreover, when advertisers' products are correlated, a higher degree of competition in the market of the advertisers' products may decrease the accuracy of the media outlet's reports.
\end{abstract}

JEL Classification: L82, D82

Keywords: Advertising, Media accuracy, Two-sided market, Competition, Commercial Media Bias

${ }^{*}$ We are very grateful to seminar audiences at University of Essex, Copenhagen Business School, CERGE-EI, University of Bologna, IMT Lucca, the 10th journées Louis-André Gérard-Varet, Max Weber Programme Lustrum Conference, the 2nd Ravello Workshop, Bomopa Economics Meetings 2011, the EUI-FSR Workshop "Economics of Communication and Media Markets", and at the 2010 Workshop in Media Economics and Public Policy. All remaining errors are ours.

†University of Bologna, Italy. andrea.blasco@unibo.it

${ }_{\ddagger}^{\ddagger}$ Dipartimento di Economia Politica e Statistica, University of Siena, Italy. paolo.pin@unisi.it.

${ }^{\S}$ IMT Lucca, Italy. f.sobbrio@imtlucca.it 


\section{Introduction}

Advertisers and media live in a symbiotic relationship. Advertisers need media to reach their consumers and media needs advertisers to finance their activities and to make profits. This is true for any type of media. ${ }^{1}$ Moreover, this relationship becomes even more stringent for media whose revenues depend exclusively on advertising (commercial $\mathrm{TV}$, radio, online newspapers, blogs, free-press, etc.).

The traditional economic literature on advertising (see Bagwell, 2007) has been typically focused on understanding the economic rationale behind advertising (e.g., persuasive or informative advertising) while keeping media outside of the analysis. More recently, the literature on two-sided markets has found in the media one of its archetypal platforms. Specifically, a platform connecting advertisers and consumers (Anderson and Gabszewicz, 2006; Armstrong, 2006). This literature has analyzed the interactions between media and advertisers in a two-sided market where media sell the medium content to media viewers and, at the same time, media sells the access to such viewers to the advertisers. ${ }^{2}$

Less attention has been devoted to the understanding of the advertising value of the medium content itself. Advertisers may want to influence medium content for two main reasons. First, advertisers may want the media to choose specific types of content to attract (i.e., target) more valuable categories of viewers/consumers. ${ }^{3}$ On the other hand, advertisers may want to specifically influence the information content of the media to influence the consumption decision of any viewer. Indeed, as already noted by Downs (1957), consumption is one of the reasons why people desire information (along with entertainment, voting and production). That is, viewers value media reports (also) because they may provide valuable information on consumer products. A recent survey of 27,000 individuals in 55 countries pointed out that, prior to choosing an electronic product, $57 \%$ of consumers read products' reviews. Similarly, $45 \%$ and $37 \%$ of individuals consult reviews before choosing a car or software, respectively. ${ }^{4}$ Hence, advertisers' profits in the market for products ultimately depend on how (and how many) consumers are influenced by the news reports coming from the media, which in turn may affect the advertisers' willingness/ability to pay the media. Consequently, the relationships between advertisers and media outlets may go well beyond the simple sales of advertising space and the traditional rationales for advertising.

In this paper, we abstract from standard rationales for advertising (i.e., persuasive or informative advertising) in order to explicitly focus on an environment where media

\footnotetext{
${ }^{1}$ Excluding few TV stations funded exclusively through subscriptions.

${ }^{2}$ Hamilton (2004) refers to selling the access to viewers as selling "eyeballs".

${ }^{3}$ See Gabszewicz et al., 2001, 2002; George and Waldfogel, 2003; Hamilton, 2004; Strömberg, 2004; Gal-Or et al., 2010; Bergemann and Bonatti, 2010.

${ }^{4}$ Source: Nielsen "Global Trends" June 2010.
} 
offer the medium information content to media viewers and, at the same time, they sell a bundle to advertisers constituted by such viewers and the medium information content. That is, how much advertisers are willing to spend will depend on how many consumers they may reach trough the medium and what kind of information the medium is releasing. Moreover, unlike targeted advertising, in our model an advertiser wants to influence content not to attract specific types of viewers/consumers but to influence viewers/consumers' beliefs regarding products' qualities. Specifically, in our model there is a media outlet who observes information about the quality of firms' products and that may use such information when bargaining over advertising fees.

To fix the ideas on the basic intuition of our model consider the following example. The media outlet is a magazine specializing in computer products. Suppose there are two firms (e.g., Acer and Toshiba) and the magazine gathers information on whether each firm has a bad quality product (e.g., a defect) or not, i.e., it gets a signal on each firm's product. Each firm would never want the media outlet to publish negative information (if any) on its product. On the other hand, it may benefit from the media outlet publishing negative information (if any) on the rival's product. Hence, when contracting for the cost of advertising, if the magazine found negative evidence on either or on both firms, it can use such information to charge a higher advertising fee to either firm. That is, advertisement expenditures may end up being a hidden form of payment aimed at either concealing negative information about the advertiser's own product (paying positive to avoid negative) or at revealing negative information about the competitors' products (paying positive to go negative). Hence, while in our model the only advertisements consumers watch are indeed "positive" (and do not provide any information per se), such advertisements may hide an implicit payment to obtain a "negative advertisement" in the form of media disclosing negative information about a competitor's product. ${ }^{5}$

We generalize the above reasoning to provide an economic rationale for the observed differences in the accuracy of media reports on advertisers' products. Every day, we observe media reporting negative news on consumers products. Recent examples include Toyota with its malfunctioning car accelerators, the IPhone 4 signal reception issues, Toshiba's episodes of over-heating and fire in some of its laptop series. Indeed, for example, the core business of many consumer magazines and websites is exactly based upon providing reviews of consumers' products and to point out the presence of issues in such products (e.g., PC Magazine, PC World, Consumer Reports, Consumer Digest, Runner's World, Wine Spectator, Zagat). At the same time, there is anecdotal evidence of significative under-reporting in the coverage of news on specific products/issues due to advertisers'

\footnotetext{
${ }^{5}$ For the interested reader, the online appendix provides few examples consistent with the rationale of "paying positive to go negative".
} 
pressure on media. In the US, the pressure of tobacco advertisers had lead the media to not disclose, for many years, any information about the health related risks of smoking (Baker, 1994; Bagdikian, 2004; Chaloupka and Warner, 2000). Pharmaceutical companies also seem to exert significant pressure on the editorial decisions of medical journals (Fletcher, 2003; Fugh-Berman et al., 2006). ${ }^{6}$ In a notorious case, the executive editor of Transplantation and Dialysis rejected a guest editorial questioning the efficacy of epoetin in end stage renal disease, despite favorable peer review, because, as he wrote to the author, "it went beyond what our marketing department was willing to accommodate" (Dyer, 2004). ${ }^{7}$ The conspicuous advertisements of car manufactures also seem to represent one of the key factors leading media to present evidence on the sources of global warming which appear to be largely unbalanced with respect to the consensus within the scientific community (Oreskes, 2004; Boykoff and Boykoff, 2004; Ellman and Germano, 2009). This type of advertisers-induced distortion in the accuracy of news reports is referred to as "commercial media bias" or "self-censorship" (Ellman and Germano, 2009; Germano and Meier, 2010). Nevertheless, products defects, the dangerous effects of smoking, the ineffectiveness of a drug product, the effects of car pollution on global warming, are all news likely to negatively affect the revenues of the advertiser whose product is the subject of such news. Hence, it is somewhat puzzling to observe that this "commercial media bias" has arisen only in some of these cases. The present paper provides a simple rationale that explains these differences. Specifically, we show that whether or not advertisers' pressure on media has negative consequences on the accuracy of media reports ultimately depends on the extent of correlation among advertisers' products. That is, "commercial media bias" is likely to arise or not depending on whether the competition in the products' market also translates into competition over media contents. When the correlation in products' qualities is high, all firms share the same preferences on media reports (i.e., every firm wants media to not refrain from disclosing any negative information about any product since such news would hurt the sales of its own product). Hence, in this case, advertisers compete in the market for products but they do not compete over media reports. When instead this correlation is low, firms have conflicting preferences over media contents (i.e., "bad" firms want to pay positive to avoid negative and "good" firms want to pay positive to go negative). Hence, advertisers compete both in the products market and over media contents. Therefore, when advertisers' products

\footnotetext{
${ }^{6}$ In 2010, Pharmaceutical Companies spent $326 \$$ millions on advertising in medical journals (IMS Health 2010). Pharmaceutical companies may also finance medical journals through "sponsored subscriptions" (Fugh-Berman et al., 2006).

${ }^{7}$ The article also suggested that the Medicare spending on this treatment was unjustified given the limited benefits for patients. Medicare spent over $\$ 7.6$ billions on epoetin between 1991 and 2002 (Dyer 2004). Specifically, two different drug companies produce two products (i.e., Procrit and Epogen) both using epotein as their main component (source: medicinenet.com/epoetin_alfa).
} 
are weakly correlated, "commercial media bias" is endogenously swept away by the advertisers' competition over news contents. Instead, in the presence of a high degree of correlation among advertisers' products, "commercial media bias" represents a serious concern. The tobacco industry provides a straightforward example of products whose "qualities" (i.e., health risks) are almost perfectly correlated. Instead, the mobile phone industry provides an example of products whose qualities are weakly correlated. Consistent with anecdotal evidence, the model predicts that in the first case media are likely to hide any negative information observed, while in the second one media are likely to disclose it. Therefore, our model provides testable empirical implications that could help better guide the empirical literature examining the link between advertising and news contents.

Since consumers have rational expectation, the endogenous level of media outlet's viewership is decreasing in the degree of correlation as well, i.e., fewer consumers would find it worthwhile to watch the media outlet's reports. In turn, this implies that the media outlet's expected profits will also be lower. In other words, the higher the advertisers' pressure on the media outlet to hide negative information, the less "credible" (i.e., accurate) its news reports will be and thus the lower the profits that it ends up earning. Finally, we also analyze the role played by competition in the market for products on the accuracy of media reports. Specifically, we show that, while in the case of uncorrelated products a higher degree of competition always leads to a higher accuracy of news reports, this is not always the case when products qualities are correlated. That is, an increase in competition in the market for products may be associated with lower news accuracy (i.e., more "commercial media bias"). Thus, while a high degree of competition among firms with conflicting preferences over news reports is beneficial for consumers, this may not be the case when firms share similar preferences over news contents. Overall, our analysis suggests that media regulators should target their monitoring efforts towards news contents/issues where advertisers are likely to share similar preferences.

\section{Related Literature}

Our paper is closely related to the literature examining the link between advertising and news contents in a two-sided market. ${ }^{8}$ There are two different issues analyzed within this literature. The first one looks at how targeted advertising may interact with news content (Gabszewicz et al., 2001, 2002; George and Waldfogel, 2003; Hamilton, 2004; Strömberg, 2004; Gal-Or et al., 2010; Bergemann and Bonatti, 2010). This literature suggests that given a constraint in the number of news that can be reported (or time

\footnotetext{
${ }^{8}$ See Anderson and Gabszewicz, 2006, for an extensive survey on advertising in two-sided markets.
} 
slots in a broadcast schedule), advertisers may influence media to induce them to choose news that interests the most valuable consumers. This may create distortions since, for example, advertisers may want news contents to cover only issues preferred/relevant to large groups (Gabszewicz et al., 2001, 2002; Strömberg, 2004). The second one is a complementary approach looking at how accuracy of news reports may directly affect the purchasing decision of consumers and thus advertisers' profits (Ellman and Germano, 2009; Germano and Meier, 2010). Ellman and Germano (2009) show that, if an advertiser could commit to withdraw its ads as a reaction to unfavorable news coverage, it may induce the media outlet to not publish such information. Germano and Meier (2010) focus on a similar issue by looking at $n$ media outlets located on a network within the Chen and Riordan's (2007) spokes model. ${ }^{9}$ The authors show that if the number of media outlets is too small (or if there are too few owners), self-censorship by media outlets would arise endogenously. ${ }^{10}$ The present paper is closely related to this second line of research. ${ }^{11}$ Specifically, there are two main features that make our contribution complementary to the existing literature.

First, both Ellman and Germano (2009) and Germano and Meier (2010) focus on the case where, for a given level of circulation, the net effect of increasing accuracy on a media outlet's advertising revenues is negative. Instead, we do not make any prior assumption on this effect. While any advertiser would want a media outlet to always conceal any negative information regarding its own product, such advertiser may have different preferences regarding the disclosure of negative information about the competitor's products depending on the correlation structure. That is, we show that when allowing advertisers to compete over news contents, the media incentives to produce truthful reports are not necessarily misaligned with the advertisers' ones. Specifically, whether advertisers have a negative influence on the accuracy of media reports or not, would be endogenously determined by the structure of the correlation in the products' industry. ${ }^{12}$

Second, while the above papers look at how competition in the media industry may increase the accuracy of media reports, while keeping constant the preferences of advertisers

\footnotetext{
${ }^{9}$ See also Germano (2009) for an analysis of the "uncovered" case of the spokes model.

${ }^{10}$ Clearly, advertising may also have other types of negative effects on viewers. Armstrong and Weeds (2007) provide a model where advertising-funded media may create a welfare loss with respect to other funding schemes (i.e., public broadcasting) due to the disutility of ads. Roger (2010) shows that, in a two-sided market with vertical differentiation, the presence of advertising creates a downward distortion in the quality chosen by the top media platform.

${ }^{11}$ See also Petrova (2011) for a model on media bias analyzing the interaction between advertising revenues and special interests groups' subsidies.

${ }^{12}$ Germano and Meier (2010) consider in an extension a case where competing advertisers have different preferences over accuracy of news reports, however they still assume that the overall (mean) effect of increasing accuracy on a media outlet's advertising revenues is negative. In line with the rationale behind our result, Petrova (2011) shows that media bias is lower when special interest groups have misaligned preferences.
} 
for low accuracy, we focus on the complementary research question. That is, we show how and when advertisers' competition in the products market may increase the accuracy of media reports even in the presence of a monopolistic media outlet.

In recent years, there has been a growing empirical literature looking at advertising expenditure and media coverage (Reuter and Zitzewitz, 2006; Di Tella and Franceschelli, 2009; Rinallo and Basuroy, 2009; Reuters, 2009; Gambaro and Puglisi, 2010). This literature usually finds a positive correlation between advertising expenditure and favorable media coverage. However, it also shows that this link weakens or disappears in contexts where there is higher advertisers competition over media contents. Specifically, Reuter and Zitzewitz (2006) find a positive relation between mutual fund recommendation and advertising expenditures for personal finance media while no correlation for national newspapers. Rinallo and Basuroy (2009) find that preferential coverage of the advertisers' products is weaker when the media outlet's advertising revenues are more diversified. Reuter (2009) finds weak evidence of a correlation between wine ratings and advertising in Wine Spectator. Thus, consistent with the predictions of our model, this recent empirical evidence seems to suggest that the stronger the competition among advertisers with conflicting preferences (e.g., more advertisers competing over media contents or lower correlation among advertisers' products), the higher the probability that a media outlet would report accurate information. ${ }^{13}$

Formally, our paper is related to the model of Besley and Prat (2006) on media capture by incumbent politicians. Specifically, our signal structure builds upon the one present in their paper. Furthermore, we model the effects of conflicting preferences over news contents as a principal-multiple agents game with multilateral externalities (see Segal, 1999). That is, the media outlet acts as a principal making simultaneous bilateral offers to multiple agents (i.e., the potential advertisers) and the news on products' qualities, reported by the media outlet to informed consumers, depend on the set of accepted offers. Moreover, this information creates externalities since it affects the agents' payoffs. In such a setting, as shown by Segal (1999), when the set of feasible contracts is unrestricted, the principal is able to maximize its rents by offering a contract involving the harshest possible punishment to the agents rejecting its offer. Similarly, in our framework, the

\footnotetext{
${ }^{13}$ Historical evidence also seems to suggest that the overall impact of advertising on the accuracy of media reports is not necessarily negative. Gentzkow et al. (2006) focus on the US newspaper industry between the end of the 19th century and the beginning of the 20th century. They show that technological changes (i.e., decreasing production costs) induced significative economies of scale and an increase in competitiveness of the newspaper industry. In turn, these changes increased advertising revenues which contributed to create an independent press. Petrova (2010) focuses on the US press in the 1880s and shows that a higher profitability of advertising in local markets leads to the presence of more independent newspapers. Poitras and Sutter (2009) look at the decline in muckraking by US magazines at the beginning of the 20th century. They find no evidence in support of the hypothesis that such decline was the results of advertisers' boycott as a reaction to adverse news coverage. See also Blasco and Sobbrio (2011) for a survey of the empirical and theoretical literature on "commercial media bias".
} 
media outlet has full bargaining power with respect to bad quality producers. Therefore, it is always able to extract all the profits they obtain in the market of informed consumers. In turn, this leads to the presence of a clear link between the externality created by the media outlet's news reports and the degree of correlation in the distribution of agents' types. Finally, we also show that the maximization of the media outlet's profits is not necessarily associated with accurate news reports. That is, the model provides insights on how the rent extraction process pursued by the media outlet may positively or negatively affect informed consumers.

Finally, our results on the beneficial effects of competition among agents with conflicting preferences on the availability of accurate information, is similar to the spirit of Dewatripont and Tirole (1999). However, their setting and their focus are rather different from ours. In their model, competition between agents with conflicting preferences is beneficial because it alleviates the moral hazard problem of agents directly involved in information acquisition. Instead, in our framework, information acquisition is not subject to moral hazard. Moreover, when agents have conflicting preferences over the disclosure of information by a third party (i.e., the media outlet), competition is beneficial because the willingness to pay of the agent in favor of information disclosure (i.e., the "good" quality firms) is always at least as high as that of the opposite party (i.e., the "bad" quality firms).

The paper is structured as follows. Section 3 describes the general model. Section 4 characterizes the media outlet's equilibrium news reports as a function of the number of firms competing in the market for products and of the correlation among products qualities. Section 5 analyzes how the accuracy of the media outlet's reports influences the equilibrium fraction of informed consumers. Section 6 discusses how the degree of competition in the market for products affects the accuracy of news reports. Section 7 provides some robustness checks results of the benchmark model. Section 8 concludes. A formal definition of the equilibrium of the game is given in Appendix A, while all the proofs are provided in Appendix B.

\section{The Model}

There is a single media outlet and a set $\mathcal{L}$ of firms, with $L=|\mathcal{L}|$. Each firm is producing a good for a unit mass of potential consumers. Ex ante all products are identical. However, each firm may experience a negative shock in the quality of its product when the product is already in the marketplace (e.g., a defect). That is, the quality of firm l's product, $q_{l}$, may turn out to be either good (i.e., $q_{l}=g$ ) or bad (i.e., $q_{l}=b$ ). In other words, Nature selects a set $\mathcal{B}$ of firms with a bad quality product, i.e., $q_{l}=b, \forall l \in \mathcal{B}$. 
Consumers. Consumers are risk neutral and demand (at most) one product. Each consumer derives a positive utility $u_{g}$ from consuming a good quality product and (zero) utility $u_{b}$ from consuming a bad quality one. However, consumers have also the option to decide to not consume any of the products offered by the $L$ firms if they are not satisfied with the expected quality of any product. Specifically, we assume that a consumer prefers to stick with her "status quo" utility $u_{0}$ rather than consuming a bad quality (i.e., defected) product. That is, consumers are happy to consume a good quality product but they prefer to use their outside consumption option (e.g., keep using an old product) rather than ending up using a bad quality or defective product, i.e., $u_{g}>u_{0}>u_{b}=0$.

Information structure $\mathcal{B}$ is private information of Nature, however the distribution of the number of bad quality products, i.e., $B=|\mathcal{B}|$, is common knowledge for all agents (i.e., firms, consumers and the media outlet). Specifically, $B$ is distributed according to a discrete probability distribution $\mathcal{P}$. In order to encompass a wide range of industry structures (i.e., of possible correlation structures among negative shocks in products' qualities), we do not impose any prior restriction over $\mathcal{P}$. That is, $\mathcal{P}$ is characterized by only two elements: $i$ ) the corresponding p.m.f. and c.d.f. $p(n)$, i.e. the probability of having $n$ bad products; $i i)$ the average fraction of good quality products, i.e., $\nu \in(0,1) .{ }^{14}$ The media outlet, along with all producers, observes a signal $z_{l} \in\{\varnothing ; b\}$ for each product $l$. That is, all producers and the media outlet observe a vector of signals $\mathbf{z}=\left\{z_{1} ; \ldots ; z_{L}\right\}$ on products qualities.

If product $l$ is a good quality one (i.e., $l \notin \mathcal{B})$ then $\operatorname{Pr}\left(z_{l}=\varnothing \mid q_{l}=g\right)=1$ (i.e., there will never be any evidence on the presence of a defect in the product). Instead, if product $l$ is a bad quality one (i.e., $l \in \mathcal{B})$ than signal $b$ is realized with probability $\theta \in(0,1]$, i.e., $\operatorname{Pr}\left(z_{l}=b \mid q_{l}=b\right)=\theta$. Hence, $\theta$ represents the probability of detecting a bad quality product. Moreover, we denote as $B_{\theta} \leq B$ the number of bad signals contained in $\mathbf{z}$ (i.e., the number of bad quality products discovered by the media outlet and firms). ${ }^{15}$

Once the media outlet has received the vector of signals $\mathbf{z}$, it has to produce a news report regarding the $L$ products. Such a news report by the media outlet consists in a vector of messages $\mathbf{m}=\left(m_{1} ; \ldots ; m_{L}\right)$. Moreover, signals are hard information, i.e., the media outlet may conceal but not forge information. Hence, the vector of messages

\footnotetext{
${ }^{14}$ Clearly $i$ ) implies $i i$ ), as $\nu=1-\sum_{i=0}^{L} i p(i)$. Second, $\left.i\right)$ is sufficient to characterize $\mathcal{P}$ because firms are ex-ante homogeneous. For instance, if products' qualities are uncorrelated, then it is simply the case that $\nu=\operatorname{Pr}\left(q_{l}=g\right)$ and $(1-\nu)=\operatorname{Pr}\left(q_{l}=b\right)$. That is, in this case $\nu$ would simply represent the prior probability of any product being a good quality one. Instead, in the opposite case of perfect correlation, $\nu=p(L)$ and $(1-\nu)=p(0)$. That is, in this case $v$ would be the prior probability of all firms having a good quality product.

${ }^{15}$ Notice that, like Besley and Prat (2006), we assume that signals can only be bad. However, as in their model, the framework could be extended to incorporate good signals, as long as the probability of receiving a good signal is lower than the probability of a bad one. That is, from the media outlet's perspective, not observing any signal would increase the probability of the product being of good quality.
} 
m must be consistent with the set of signals observed. Specifically, m $\in \mathcal{M}$ where $\mathcal{M}=\left\{\left(m_{1}, \ldots, m_{L}\right): m_{l} \in\left\{\varnothing \cup z_{l}\right\} \forall l \in \mathcal{L}\right\}$ represents the message space of the media outlet contingent on $\mathbf{z}$.

Informed consumers Since the media outlet's report may be informative for her consumption decision, a consumer may decide to become informed before choosing a product. Specifically, in order to access the media outlet's report $\mathbf{m}$, consumer $i$ has to incur in an opportunity cost $c_{i} \sim U[0, c]$ (i.e., pay $c_{i}$ to observe $\mathbf{m}$ ), where $c$ is the upper-bound on such opportunity cost. ${ }^{16}$ Then, if a consumer decides to watch the media outlet's report, she updates her beliefs accordingly and she decides which product to consume, if any. Specifically, the expected utility of a consumer (net of the opportunity cost of acquiring information) when watching the media outlet's report is:

$$
U^{I}(m)=\max \left\{\arg \max _{l} E_{\mathcal{P}}\left[u\left(q_{l}\right) \mid \mathbf{m}\right] ; u_{0}\right\}
$$

where $E_{\mathcal{P}}$ represents the expectation operator given $\mathcal{P}$. That is, since $u_{b}=0$, then $E_{\mathcal{P}}\left[u\left(q_{l}\right) \mid \mathbf{m}\right]=\operatorname{Pr}\left(q_{l}=g \mid \mathbf{m}\right) \cdot u_{g}$. Instead, the expected utility of remaining uninformed is simply:

$$
U^{U}=\max \left\{\nu \cdot u_{g} ; u_{0}\right\}
$$

In the rest of the analysis we focus, without loss of generality, on the most general case where $u_{0} \leq \nu \cdot u_{g}$. That is, when not watching the media outlet's report, a consumer finds it optimal to (randomly) choose one of the products offered by the $L$ firms. Hence, consumer $i$ will be willing to watch the media outlet's report if and only if:

$$
c_{i} \leq E_{\mathcal{P}}\left[U^{I}(\mathbf{m})\right]-U^{U}
$$

Therefore, the expected fraction of informed consumers will be:

$$
\alpha=\frac{E_{\mathcal{P}}\left[U^{I}(\mathbf{m})\right]-\nu \cdot u_{g}}{c}
$$

Consumers have rational expectations regarding the media outlet's reporting strategy. For instance, if the media outlet were to always conceal any negative information about all products, its report would be uninformative. Consumer would anticipate this, thus, $\alpha$ would be equal to $0 .{ }^{17}$

\footnotetext{
${ }^{16}$ Without loss of generality, we consider $c \geq \nu \cdot u_{g}$. That is, there are some consumers who never find optimal to become informed.

${ }^{17}$ Notice that if, for example, the media outlet also had an entertainment value for its viewers, some consumers would be willing to watch the media outlet even in presence of uninformative reports. That is, there would exist a lower bound $\alpha^{\mathrm{min}}$ in the fraction of "informed" consumers.
} 
Advertising fees and Media outlet's profits Before deciding what information to report to viewers, the media outlet may bargain with producers over the advertising fees, by using the information that it obtained on the quality of their products (i.e., $\mathbf{z}$ ). This bargaining process takes place into two stages. In the first stage, the media outlet makes an offer to each firm $l \in \mathcal{L}$. Specifically, the media outlet asks an advertising fee $t_{l}$ to each firm contingent on a media outlet's news report $\mathbf{m}$ and for a given expected fraction $\alpha$ of informed consumers. Then, firms observe all the offers of the media outlet and, in the second stage of this bargaining process, they simultaneously decide whether to accept their own offer or not. ${ }^{18}$ That is, firm l's action is simply $a_{l} \in \mathbb{A}=\{A, R\}$ where $A$ stands for "Accept" and $R$ stands for "Reject". Then, the media outlet's offer to firm $l$ is $\tau_{l}\left(\mathbf{m}, a_{l}\right) \in \mathcal{C}\left(\mathcal{M}, \mathbb{A}, \mathbb{R}_{+}\right)$where $\mathcal{C}$ is the set of all functions $\tau: \mathcal{M} \times \mathbb{A} \rightarrow \mathbb{R}_{+}$. Specifically, $\tau_{l}\left(\mathbf{m}, a_{l}\right)$ involves an advertising fee $t_{l}>0$ to be paid by firm $l$ to the media outlet contingent on firm $l$ accepting this offer and the media outlet reporting $\mathbf{m} .{ }^{19}$ The media outlet's profits are given by the sum of the advertising fees $t_{l}$ collected from producers, given its news report:

$$
\Gamma(\mathbf{m}, \tau, \mathbf{a})=\sum_{l \in \mathcal{L}} \tau_{l}\left(\mathbf{m}, a_{l}\right)
$$

Notice that, since the aim of our study is to analyze the advertisers' influence on the accuracy of news reports, the media outlet's profits do not directly depend on the number of viewers. ${ }^{20}$ That is, we focus on the incentives to produce truthful reports coming from the advertisers' side, while abstracting from the ones coming from the consumers' side per se (i.e., profits from viewership independent from advertising). At the same time, we assume that, when indifferent between two news reports yielding the same profits, the media outlet will always choose the most informative one. ${ }^{21}$ This tie-breaking rule is simply implying that, all other things equal, the profits of the media outlet are increasing in the informativeness of its messages (e.g., reputation concerns).

\footnotetext{
${ }^{18}$ Notice that analogous to the setting of Besley and Prat (2006), since agents are risk neutral nothing would change if the media outlet were to make its offers before observing the vector of signals (i.e., the media outlet would ask to each firm for a fee equal to the expected value of all possible message-contigent fees).

${ }^{19}$ Notice that the media outlet is allowed to make conflicting offers at the bargaining stage. For example, the media outlet may ask firm 1 to pay $t_{1}>0$ to hide $z_{1}=b$ and, at the same time, ask firm 2 to pay $t_{2}>0$ to reveal $z_{1}=b$. However, even if both firms accept these offers, the media outlet cannot be paid by both. That is, clearly, the payments are contingent on the media outlet's message. That is, in the above example, the media outlet may either hide $z_{1}=b$ and then be paid $t_{1}$ by firm 1 or, in alternative, it may reveal $z_{1}=b$ and then be paid $t_{2}$ by firm 2 .

${ }^{20}$ Which, indeed, is the case for many types of media such as commercial TV, online newspapers, radio, free-press, etc.

${ }^{21}$ That is, the following tie-breaking rule applies: let $D$ and $D^{\prime}$ be the number of bad quality signals disclosed by the media outlet given messages $\mathbf{m}$ and $\mathbf{m}^{\prime}$. Then, if $\Gamma(\mathbf{m})=\Gamma\left(\mathbf{m}^{\prime}\right)$ and $D>D^{\prime}$, then $\mathbf{m} \succ \mathbf{m}^{\prime}$
} 
Producers Producers aim at maximizing their total sales in the market for products, i.e., maximizing their market share (as in Ellman and Germano 2009 and Germano and Meier 2010). Clearly, firm l's final sales are given by the share of consumers who end up choosing its product. Hence, the profits of firm $l$, given the media outlet's report $\mathbf{m}$, are:

$$
\Pi_{l}\left(\mathbf{m}, a_{l}, \alpha\right)=S_{l}(\mathbf{m}, \alpha)-\tau_{l}\left(\mathbf{m}, a_{l}\right)
$$

where $S_{l}(\mathbf{m}, \alpha)$ denotes the total market share of firm $l$ as a function of the media outlet's report $\mathbf{m} .^{22}$

To summarize the timing of the game is as follows:

1. Nature determines which products experience a negative shock (i.e., ex-post quality $\left.q_{l}, \forall l\right)$.

2. The media outlet and the firms observe $\mathbf{z}$.

3. The media outlet asks an advertising fee $\tau_{l}$ to each firm contingent on the news report $\mathbf{m} \in \mathcal{M}$.

4. All firms simultaneously decide whether to accept the media outlet's offer or not.

5. Given the set of accepted offers, the media outlet selects $\mathbf{m}$ (consistent with $\mathbf{z}$ ) to maximize its profits.

6. Every consumer $i$ decides whether to incur the opportunity $\operatorname{cost} c_{i}$ to watch the media outlet's report and if so she updates her beliefs on products' qualities.

7. Consumers choose the product(s) with the highest expected quality.

Notice that, while consumers expectations must be correct ex-post, at the bargaining stage between the media outlet and producers, the fraction of informed consumers $\alpha$ will be considered as fixed (since expectations are formed before observing the outcome of this bargaining game). Therefore, the equilibrium of the game has two components. The first is the Nash equilibrium of the bargaining game between firms and the media outlet (for any given level of $\alpha$ ). The second is the rational expectation equilibrium represented by the equilibrium fraction of informed consumers, i.e., $\alpha .^{23}$

Indeed, at the bargaining stage, for any $\alpha>0$, the media outlet may have an incentive to conceal negative information about firm $l$ (if any) in exchange of a transfer $t_{l}>0$ from

\footnotetext{
${ }^{22}$ There are two implicit assumptions in this setting (without loss of generality). First, the total value of the market is normalized to one. Second, whenever indifferent, any producer would accept the media outlet's offer.

${ }^{23}$ See the Definition A in Appendix A for a formal characterization of the equilibrium of the game.
} 
each producer whose profits would be negatively affected by publishing such information. At the same time, depending on the structure of the correlation among products' qualities, a firm may also be willing to pay a positive transfer to the media outlet in order to publish negative information about its competitor. ${ }^{24}$ Hence, as it is shown in the equilibrium analysis below, the advertising fees that the media outlet can obtain from producers are an increasing function of $\alpha$. Thus, although the media outlet does not directly care about the fraction of people watching its report, its profits indirectly depend on it. Hence, the model embeds the typical structure of a two-sided market. Specifically, the price (i.e., ads fee) that agents on one side of the market (i.e., advertisers) are willing to pay to the platform (i.e., the media outlet) depend on how many agents on the other side of the market are willing to access the platform (i.e., fraction of informed consumers $\alpha$ ). Moreover, the fraction of informed consumers is also endogenous since it depends on rational expectations over the equilibrium strategies of the media outlet and of the advertisers.

The next two sections present the formal analysis of the effects of competition among potential advertisers on the equilibrium news reports of the media outlet. Specifically, we first characterize the possible equilibria of the bargaining game between the media outlet and producers. Then, we analyze the equilibrium fraction of informed consumers consistent with such equilibria.

\section{Advertisers' competition and media outlet's re- ports}

In this section we analyze the bargaining sub-game. Specifically, we discuss the preferences of potential advertisers over news reports and then analyze which signals the media outlet will find optimal to disclose to viewers in equilibrium. That is, we analyze the equilibrium disclosure strategy of the media outlet for a given fraction of informed consumers (i.e., for a given $\alpha$ ). Then, proceeding backwards, in the next section we will analyze the endogenous equilibrium fraction of informed consumers.

In the last stage of the game, informed consumers will only choose products whose expected quality is high enough (i.e., such that $\left.E_{\mathcal{P}}\left[u\left(q_{l}\right) \mid \mathbf{m}\right] \geq u_{0}\right)$. Hence, the media

\footnotetext{
${ }^{24}$ Notice that, unlike the literature on informative advertising (e.g., Nelson, 1974; Butters, 1977; Grossman and Shapiro, 1984; Milgrom and Roberts, 1986; Dukes, 2004), in our model advertising does not convey or signal any information to viewers per se. In our framework, advertising indirectly influences viewers' information by shaping the media outlet's incentives to disclose its information. Indeed, a higher level of advertising may be associated with a higher or lower level of information of consumers on the firms' products depending on whether ads are paid to reveal or to hide information. In addition, advertising does not have any signaling value in our model since viewers do not observe the advertising fees paid by firms.
} 
outlet's report is going to affect the market share of each producer. Disclosing negative information about firm l's product will clearly have a negative impact on its market share. At the same time, its competitors may benefit from the disclosure of such negative news depending on the structure of the correlation among the negative shocks in products' qualities in a specific industry. Intuitively, when the correlation is low or null (i.e., uncorrelated shocks), then a firm is likely to gain from bad news about its competitors' products. Instead, when products' qualities are highly correlated (e.g., health risks of different tobacco products on consumers' health) a firm is likely to be hurt by negative news about its competitors' products. Hence, given the set of signal observed $\mathbf{z}$, the media outlet will anticipate which producers would be willing to pay an ads fee to disclose (pay positive to go negative) or to hide (pay positive to avoid negative) bad news on a given product. That is, the media outlet may ask each producer for an ad fee as high as the additional profit that the producer may earn in the market for informed consumers if the media outlet produces a favorable report (e.g., hides or discloses a given set of signals). ${ }^{25}$

The following sections develop this basic intuition in detail and provide a formal analysis of the media outlet's equilibrium news reports within a given competition (i.e., duopoly or an arbitrary number of producers) and correlation (i.e., uncorrelated or correlated qualities) structure of the market of the advertised products. Specifically, for clarity of exposure, we first provide the basic results for the benchmark case where products are uncorrelated. Then, we present the general propositions for the case where firms face correlated shock in the quality of their products. Without loss of generality, in the following analysis we normalize $u_{0}=1$.

\subsection{Benchmark: Uncorrelated products}

In order to develop the basic intuition behind the general model, this section focuses on the case where the negative shocks in products' qualities are uncorrelated ( $q_{l}$ are i.i.d.). We first describe the equilibrium in the simplest case where there are only two potential advertisers (i.e., $l_{1}$ and $l_{2}$ ) competing in the products market. Then we generalize and prove the result for the case of an arbitrary number of producers.

\footnotetext{
${ }^{25}$ As an analogy, we may think of this framework as if the media outlet was selling tickets (entry costs) to bad quality firms (i.e. firms whose product the media outlet discovered being of bad quality) in order to access the $\alpha$-market share of informed consumers. On the other hand, the media outlet could also sell a ticket to "good" quality firms (i.e. firms whose product the media outlet did not find being to be of bad quality) to restrict the bad quality firms to access this $\alpha$-market share of informed consumers.
} 


\subsubsection{Duopoly}

When products' qualities are uncorrelated, competing producers have always conflicting preferences over news reports. Suppose, for example, that $\mathbf{z}=(\varnothing, b)$. Then, $l_{2}$ would like the media outlet to not disclose such a negative signal on its product to viewers while $l_{1}$ would want the media outlet to disclose it. That is, the media outlet knows that a "good" quality producer is willing to "pay positive to go negative". On the other hand, a bad quality producer is willing to "pay positive to avoid negative". Similarly, if $\mathbf{z}=(b, b)$, each producer would like the media outlet to hide any negative information about its own product while disclosing any negative information about the competitor's product. Therefore, when bargaining over advertising fees, the media outlet will anticipate the presence of these conflicting preferences. The following result characterizes the equilibrium news reports of the media outlet. Its proof follows from the general result given below in Proposition 1.

\section{Result 1}

Let $D^{*} \leq B_{\theta}$ be the number of bad signals disclosed by the media outlet in equilibrium given its news report $\mathbf{m}^{*}$. When firms face uncorrelated shock in the quality of their products, for $L=2$ and $\alpha>0$, then $D^{*}=\min \left\{B_{\theta}, 1\right\}$ and $\Gamma=\alpha \frac{B_{\theta}}{2}$.

Hence, informed consumers may observe two types of news reports by the media outlet. In the first scenario, the media outlet would not show any negative information about either firm. In this case, informed consumers know that this report is fully truthful since the media outlet simply did not find any negative information about either of them. Alternatively, informed consumers may observe a negative report on one of the two firms' products. In this case, they would not know whether the media outlet observed negative information about only one or both products. In the first case, such report would be truthful (and the media outlet was paid by the "good" firm to disclose such signal). Indeed, as specified by our tie-breaking rule, since the "good" and "bad" firms have the same willingness to pay, the media outlet will always prefer to choose the most informative report and thus disclose the bad signal found on one of the products. Instead, when the media outlet finds bad news about both products, it ends up being paid by one of the firms to disclose only the bad signal on its' rival product. The following section generalizes the above result to the case of an arbitrary number of producers.

\subsubsection{Multiple producers}

As in the duopoly case studied above, when producers face uncorrelated shocks in their products' quality they will end up having conflicting preferences over news reports. That 
is, each producer would like the media outlet to hide the negative information (if any) about their own product and to reveal the negative information (if any) about its competitors' product. Thus the results of the duopoly case easily extend to the case of an arbitrary number of producers. The proof follows from the general result given below in Proposition 2.

\section{Result 2}

Let $D^{*} \leq B_{\theta}$ be the number of bad signals disclosed by the media outlet in equilibrium given its news report $\mathbf{m}^{*}$. When firms face uncorrelated shock in the quality of their products, for any $L \geq 2$ and $\alpha>0$ then $D^{*}=\min \left\{B_{\theta}, L-1\right\}$ and $\Gamma=\alpha \frac{B_{\theta}}{L}$

The above result generalizes the one obtained for the case with two producers. When not all firms are found to have a bad quality product, the media outlet will always end up being paid by "good" producers to disclose all the information. Instead, when all firms are found to have a bad quality product, the media outlet will "save" just one of them. Indeed, in this case, a truthful report would lead all informed consumers to not choose any of the products of the $L$ firms and thus the media outlet could never ask any producer for a positive ads fee. Thus, in this case, the media outlet always prefers to hide one bad signal so that one single firm will capture the entire market share of informed consumers. Anticipating this, the media outlet could ask to such firm an advertising fee equal to the profits of the entire $\alpha$-market share of informed consumers. Moreover, the higher the fraction of firms whose product the media outlet finds to be of bad quality (i.e., $B_{\theta} / L$ ), the higher its equilibrium profits. Indeed, the more information the media outlet has available, the higher its bargaining power with potential advertisers.

Now that we have characterized the equilibrium news reports of the media outlet in this benchmark case of uncorrelated products, we may extend the analysis to the general case of correlated products.

\subsection{Correlated products}

This section analyzes the media outlet's equilibrium news reports when firms face correlated shocks in the quality of their products. This general correlation structure is meant to capture the possible similarities among products' characteristics. Different producers may use common inputs in their production and thus a defect in a common input may result in all of them ending up with a bad quality product. ${ }^{26}$ A complementary interpretation of this correlation is that products may have similar negative externalities on

\footnotetext{
${ }^{26}$ For example, between 2009 and 2010 the Toyota Aygo, the Citroën C1 and the Peugeot 107 all experienced a defect in their accelerator's pedal. This common shock was due to the fact that all three cars were produced at a joint venture factory. Source: "Peugeot Citroën joins Toyota and Honda in recall", The Times, February 1, 2010.
} 
consumers. For example, different tobacco products are likely to create similar health risks for consumers, different cars may produce similar quantities of pollutants and thus have similar effects on global warming and so on.

As before, we first develop the basic intuition by presenting a formal analysis of the simplest case where there are only two potential advertisers (i.e., $l_{1}$ and $l_{2}$ ) competing in the products market. Then, we generalize the result for the case of an arbitrary number of producers.

\subsubsection{Duopoly}

In order to understand how this case differs from the one of uncorrelated qualities analyzed above, let's focus again on the case where $\mathbf{z}=(\varnothing, b)$. Clearly, regardless of the industry structure, i.e., regardless of the correlation among products qualities, $l_{2}$ will always want the media outlet not to report such information to consumers. That is, $l_{2}$ would always be willing to pay an advertising fee to the media outlet in exchange for not reporting negative news about its own product (paying positive to avoid negative). Viceversa, the preferences of $l_{1}$ over the media outlet's report will depend on the industry structure. When the correlation among negative shocks in products' qualities is low, then $l_{1}$ would want the media outlet to publish a negative report on its rival' product, since this would increase its market share. Indeed, upon receiving negative reports on firm $l_{2}$, informed consumers will then choose the product of firm $l_{1}$. Thus, exactly as shown in the previous section where the correlation was null, firm $l_{1}$ will be willing to pay the media outlet to disclose the negative information about the competitor's product (paying positive to go negative). Instead, when the correlation between products' qualities is high, $l_{1}$ is likely to be hurt by the publication of negative reports on the product of firm $l_{2}$. Indeed, in this case, consumers would infer that firm $l_{1}$ is likely to have a bad quality product as well. Thus, when shocks are sufficiently correlated, both producers will share the same preferences over news reports (i.e., both want the media outlet to hide any negative information) regardless of which specific product the media outlet has found negative information about.

Then, the following proposition applies:

Proposition 1 Let $D^{*} \leq B_{\theta}$ be the number of bad signals disclosed by the media outlet in equilibrium given its news report $\mathbf{m}^{*}$. Then, for $L=2$ and $\alpha>0$ there exists a threshold in the correlation between the negative shocks in products qualities:

$$
\bar{\rho}=\frac{2\left(u_{g} \nu-1\right)+\theta(1-\nu)}{\nu\left(2 u_{g}-\theta\right)}
$$

such that: 
1. If $\rho \leq \bar{\rho}$, then $D^{*}=\min \left\{B_{\theta}, 1\right\}$ and $\Gamma=\alpha \frac{B_{\theta}}{2}$

2. If $\rho>\bar{\rho}$, then $D^{*}=0$ and $\Gamma=\left\{\begin{array}{cc}\frac{\alpha}{2} & \text { if } B_{\theta} \geq 1 \\ 0 & \text { otherwise }\end{array}\right.$

Therefore, when the correlation between the negative shocks in products' qualities is low, the intuition and the results remain identical to the ones obtained in the case of no correlation. Indeed, when correlation is sufficiently low, negative information about the product of firm $l_{2}$ would not prevent informed consumers from choosing the product of firm $l_{1}$. Thus, as in the case of no correlation, firm $l_{1}$ has an incentive to "pay positive to go negative" the media outlet. That is, when the correlation in products' qualities is low, competing advertisers still have conflicting preferences over news reports.

Instead, when such correlation is high, publishing negative information about firm $l_{2}$ will have negative consequence also on firm $l_{1}$ 's profits. Therefore, when products' ex-post qualities are highly correlated, good and bad quality advertisers end up sharing the same preferences over news reports.

Notice also that $\bar{\rho}$ is increasing in $u_{g}, \nu$ and $\theta$. That is, the higher the prior expected value of a random product and the higher the probability of detecting a bad one, the less likely bad news on product $l_{2}$ will also negatively affect firm $l_{1}$. That is, the higher $u_{g}, \nu$ and $\theta$, the lower the influence of the correlation on the updated expectations of informed consumers on the quality of firm $l_{1}$ product, given the negative information about firm $l_{2}$ 's product.

Next section shows that in presence of a higher degree of competition in the products market (i.e., $L>2$ ), this sharp difference between the media outlet's optimal disclosure strategy with low and high correlation becomes smoother.

\subsubsection{Multiple Producers}

This section presents our main results. Specifically, we generalize the results obtained in the previous section to the case of an arbitrary number of producers. At the same, we also generalize the results of section 4.1.2 to the case where firms face correlated shocks in the quality of their products. The following proposition applies.

Proposition 2 Let $D^{*} \leq B_{\theta}$ be the number of bad signals disclosed by the media outlet in equilibrium given its news report $\mathbf{m}^{*}$. When firms face correlated shock in the quality of their products, for any $L \geq 2$ and $\alpha>0$ there exists a threshold in the number of bad signals disclosed by the media outlet:

$$
\bar{D}=\sup _{h \in\{0,1, \ldots, L\}}\left\{\max _{l \in \mathcal{L}} E_{\mathcal{P}}\left[u\left(q_{l}\right) \mid D=h\right] \geq 1\right\}
$$


such that $D^{*}=\min \left\{B_{\theta}, \bar{D}\right\}$. Moreover,

1. If $\bar{D}>0, \Gamma=\alpha \frac{B_{\theta}}{L}$

2. If $\bar{D}=0, \Gamma= \begin{cases}\frac{\alpha}{L} & \text { if } B_{\theta} \geq 1 \\ 0 & \text { otherwise }\end{cases}$

Therefore, while in the duopoly case there was a stark difference between the media outlet's equilibrium report when the correlation in products' qualities was low or high, in presence of more than two producers the media outlet will hide some information (i.e., hide $B_{\theta}-\bar{D}$ bad signals whenever $B_{\theta}>\bar{D}$ ) and reveal others (i.e., disclose $D=\min \left\{B_{\theta}, \bar{D}\right\}$ bad signals on firms' products). Moreover, the maximum amount of bad signals disclosed by the media outlet in equilibrium, i.e., $\bar{D}$, depends on the degree of correlation among products' qualities. Specifically, in order to assess how the correlation among products' qualities affects the media outlet's equilibrium reports, we need to introduce a formal definition that allows to compare the degree of correlation of different discrete probability distributions.

Definition 1 (more correlated d.p.d.) Let $\mathcal{P}$ and $\mathcal{Q}$ be two discrete probability distributions on $L$ products (with the same expectation $(1-\nu)$ ). Moreover, let $1 \leq \bar{D} \leq L-1$. We define $\mathcal{P}$ as more correlated than $\mathcal{Q}$ above $\bar{D}$, if, for every $\bar{D} \leq k \leq L-1$ :

$$
\frac{p(k)}{q(k)} \leq \frac{p(k+1)}{q(k+1)}
$$

and there is at least one $\bar{D} \leq k \leq L-1$ for which the above inequality is strict.

As shown in Appendix A, the above definition of more correlated d.p.d. is consistent with a smooth mean-preserving spread, as it spreads more probability weight on the right-tail of the distribution. Then, as shown by the following corollary, the amount of information that the media outlet may find optimal to hide in equilibrium, is a non-decreasing function of the correlation among products' qualities.

Corollary 1 Given two discrete probability distribution over the negative shocks in products' qualities $\mathcal{P}$ and $\mathcal{Q}$, such that $\mathcal{P}$ is more correlated than $\mathcal{Q}$ above $\bar{D}(\mathcal{P})$, it is always the case that:

$$
\bar{D}(\mathcal{P}) \leq \bar{D}(\mathcal{Q})
$$

That is, the degree of correlation in products' qualities has a key influence on the accuracy of the media outlet's reports. The higher this correlation, the (weakly) lower the maximum number of bad signal that the media outlet will find optimal to report 
to informed consumers. Viceversa, the lower this correlation, the more likely it is that the competition in the market for product will also translate into competition over news contents. As we have discussed before, the competition of potential advertisers over news contents is beneficial for informed consumers since it gives the proper incentives to the media outlet to disclose more information. Instead, a higher correlation is associated with more aligned preferences of potential advertisers over news contents. In turn, these shared preferences lead the media outlet to reduce the amount of information disclosed to informed consumers. Hence, our results provide a microfoundation and an economic rationale behind the assumption of Ellman and Germano (2009) and Germano and Meier (2010) that advertisers share the same preferences for low accuracy of news reports. The tobacco industry, which the two papers use as an archetypal example of negative advertisers' influence on news accuracy, is clearly a case at point. Indeed, arguably, the correlation among products' qualities in the tobacco industry (i.e., the negative effects on consumers' health of different tobacco products) is very high. Thus, our model indeed predicts that all tobacco companies would collude to pay the media outlet to hide any possible negative information.

Moreover, the above result linking the correlation in the market for products and the disclosure of information by the media outlet has a clear testable empirical implication. All other things equal, we should expect media to report more accurate news (e.g., disclose more negative information about products' defects/issues) on firms belonging to industries whose products exhibit a low correlation. Moreover, even within an industry, media should be more likely to report negative news on issues upon which firms have conflicting preferences than on issues where all firms share the same preferences over news reports. For example, in the car industry a firm is likely to benefit from bad news on the quality of its competitor's product. However, the same firm may instead be hurt from news regarding the effects of car pollution on global warming. Indeed, while everyday we observe negative reports released by media on defects or problems on a specific product of a single car manufacturer, there seems to be much less disclosure regarding the effects of pollution on global warming (Oreskes, 2004; Boykoff and Boykoff, 2004; Boykoff, 2007; Germano and Meier, 2010). That is, even within an industry, there may be some issues where producers have conflicting preferences over media reports and others where they share the same preferences. Hence, empirical studies aiming at testing the influence of advertisers of media contents should take into account that media are more likely to accurately report news on issues where competing producers have conflicting preferences. Overall, the results suggest that "commercial media bias" represents a serious concern in presence of a high degree of correlation among advertisers' products. Instead, when advertisers' products are weakly correlated, "commercial media bias" is endogenously 
swept away by the advertisers' competition over news contents. Therefore, media regulators should target their monitoring efforts towards news contents/issues upon which advertisers are likely to share similar preferences.

\section{Media outlet's reports and equilibrium viewership}

We can now turn to the analysis of the endogenous media outlet's viewership (i.e., the equilibrium fraction of informed consumers) given the Nash equilibrium of the bargaining game between the media outlet and potential advertisers characterized in the previous section. Informed consumers update their beliefs about the quality of a product both when they observe news about that product (i.e., $m_{l}=b$ ) but also when they do not observe any news (i.e., $\left.m_{l}=\varnothing\right) .{ }^{27}$ Specifically, informed consumers take into account that two different outcomes may result in the media outlet not reporting any news on product $l$. It may be the case that the media outlet did not find any negative information about the advertiser's product. Or, the media outlet found such negative information but decided to conceal it. Hence, since agents have rational expectations, the equilibrium fraction of informed consumers must be consistent with the equilibrium strategy of the media outlet. The following lemma characterizes the equilibrium values of $\alpha$ for the duopoly case, consistent with the Nash equilibria of the bargaining game specified in Proposition 1,

Lemma 1 Let $L=2$, then given $\bar{\rho}$ specified in (4):

$$
\begin{aligned}
& \text { 1. For } \rho \leq \bar{\rho} \text {, then } \alpha=\frac{u_{g}}{c} \cdot(1-\nu) \nu \theta \cdot(1-\rho) \\
& \text { 2. For } \rho>\bar{\rho} \text {, then } \alpha=0 \text {. }
\end{aligned}
$$

Since informed consumers have rational expectations, they know that the media outlet would never disclose any negative information about firms belonging to industries where products' qualities face highly correlated shocks (i.e., consumers are aware of the incentives of the media outlet to please advertisers by hiding any negative information observed). That is, consumers anticipate that, given $\rho>\bar{\rho}$, the media outlet's reports would never be informative and thus they will not get informed., i.e., $\alpha=0$. In turn, this implies that the media outlet ends up earning zero profits, i.e., $\Gamma=0$. Indeed, firms anticipate that no consumer would find the media outlet's news report worth spending the opportunity cost to become informed. Thus they do not need to bother paying the media outlet to hide any negative information since none would observe them. ${ }^{28}$

\footnotetext{
${ }^{27}$ See Milgrom (1981) for an analysis of Bayesian updating upon observing "no-news".

${ }^{28}$ Obviously, this is easily generalizable. As pointed out above in section 3 , if watching the media outlet also had an entertainment value for consumers, then the lower bound of $\alpha$ would be $\alpha^{\text {min }}>0$
} 
Instead, as shown by proposition 1 , for any $\rho<\bar{\rho}$ the media outlet chooses the same optimal reporting strategy, i.e., the one adopted in the case of uncorrelated products. Nevertheless, the informativeness of news report is decreasing in $\rho$. Indeed, when observing the media outlet disclosing a bad signal on either product, informed consumers know that the higher $\rho$ is the more likely it is that the media outlet also observed a bad signal on the other product (i.e., less likely that "no news" on only one of the products is good news on that product). Hence, from the point of view of consumers the value of information is decreasing in the degree of correlation between products. In turn this implies that the equilibrium fraction of informed consumers (and hence the media outlet's equilibrium profits) is a decreasing function of $\rho$. Indeed, when $\rho<\bar{\rho}$, the equilibrium fraction of informed consumers is equivalent to the one that would arise in the uncorrelated case if the probability of detecting a bad quality product was $\hat{\theta} \equiv(1-\rho) \theta$.

Thus, overall, an increase in $\rho$ may have two different negative effects on the informativeness of the media outlet's reports. For $\rho=\bar{\rho}$, a marginal increase in $\rho$ leads the media outlet to never report any negative information about firms' products. Hence, such an increase in products' correlation leads to a (sharp) decrease in the accuracy of news reports since it changes the media outlet's optimal reporting strategy. On the other hand, for $\rho<\bar{\rho}$ a marginal increase in $\rho$ does not change the accuracy of the media outlet's reports since it does not change its optimal reporting strategy. Nevertheless, this change still leads to lower informativeness of news reports since it increases the probability of the media outlet's hiding a bad signal on one of the firms' products. $^{29}$ The following graph illustrates the equilibrium fraction of informed consumers as a function of $\nu$ in presence of different degrees of correlation in products' qualities.

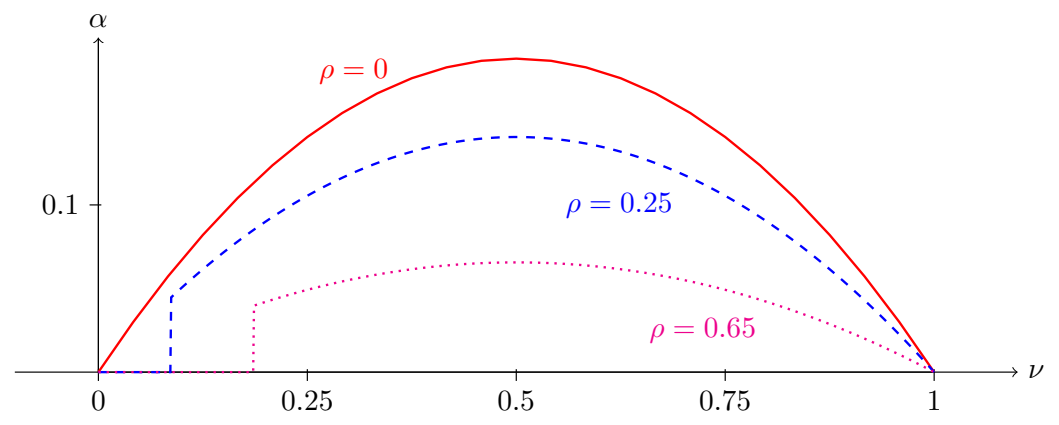

Figure 1. Equilibrium Fraction of Informed Consumers

and then $\Gamma^{\text {min }}>0$. Nevertheless, informed consumers would still not find the news reports of the media outlet credible and thus they would simply disregard them.

${ }^{29}$ Moreover, an increase in $\rho$ has a further negative effect on $\alpha$. Specifically, even when the media outlet is reporting all its information, i.e., $B_{\theta}=1$, when $\rho$ increases "no news" on product $l$ become relatively less "good news" on that product. 
As shown by the above graph, the ex-ante uncertainty on products' quality has a nonmonotonic effect on $\alpha$. Specifically, an increase in $\nu$ :

1. Always increases the informativeness of news reports. Hence, this effect tends to increase the equilibrium fraction of informed consumers.

2. Always increases the expected value of remaining uninformed. Hence, this effect tends to decrease the equilibrium fraction of informed consumers.

3.a For $\nu \in[0,0.5)$ it results in an increase in the uncertainty in the quality of the products. In turn, this effect leads to an increase in the equilibrium fraction of informed consumers.

3.b For $\nu \in[0.5,1]$ it results in a decrease in the uncertainty in the quality of the products. In turn, this effect leads to a decrease in the equilibrium fraction of informed consumers.

More generally, since the equilibrium fraction of informed consumers captures the expected informativeness of the news reports, it is possible to analyze which role the parameters of the model play on such informativeness by studying the comparative statics with respect to $\alpha$. Specifically, the following proposition characterizes these comparative statics for the general case of an arbitrary number of firms competing in the market for products.

Proposition 3 For any $L \geq 2$, the equilibrium fraction $\alpha$ of informed consumers is always non-decreasing in $u_{g}, \theta$ and $\bar{D}$, non-increasing in $c$ and non-monotone in $\nu$. Moreover, whenever $\alpha>0, \alpha$ is strictly increasing in $u_{g}, \theta$ and $\bar{D}$, and strictly decreasing in $c$.

Clearly, the more valuable a good quality product is, the more consumers find it optimal to become informed before choosing such a product. Similarly, since the expected informativeness of media reports is increasing in the probability of detecting a bad quality product and also in the amount of information that the media outlet is willing to disclose, the expected fraction of informed consumers is also increasing in $\theta$ and $\bar{D}$. In turn, since by Corollary 1, a higher degree of correlation among products' qualities leads to a (weakly) lower upper bound in the information disclosed by the media outlet, i.e., $\bar{D}$, then a higher degree of correlation is also associated with a (weakly) lower fraction of consumers willing to become informed. 


\section{Competition in the market for products and news accuracy}

This section analyses the role of competition in the market for products on the media outlet's news reports. Specifically, we explore whether a higher degree of competition in the market for products (i.e., a higher $L$ ) improves the accuracy of the media outlet's reports. In order to address this issue, we define $\varphi=\bar{D} / L$ as a measure of the accuracy of news reports. That is, the maximum fraction of bad quality products that the media outlet is willing to disclose in equilibrium, where $\varphi \in\left[0, \frac{L-1}{L}\right]$. Indeed, in the case of perfectly correlated shocks $\varphi=0$ since $\bar{D}=0$. Instead, in the case of uncorrelated shocks $\varphi=(L-1) / L$ since $\bar{D}=L-1$. Intuitively, by keeping all the other parameters of the model constant, an increase in $L$ increases the accuracy of news reports if and only if it also leads to a (more than proportional) increase in $\bar{D}$.

To analyze the effects of a "marginal" increase in competition, we compare the accuracy of news reports in presence of $L$ and $L+1$ firms. The first (trivial) comparison is the one between a monopoly and a duopoly. Clearly, when there is only one firm in the market for products (and thus only one source of advertising revenues) the media outlet will never disclose any bad information about that firm (i.e., $\bar{D}=0$ ). Hence, unless the correlation between the products in the duopoly is too high (i.e., above the $\bar{\rho}$ defined in (4)), the accuracy of news reports in a duopoly will always be strictly higher than the one in a monopoly. That is, as discussed in the previous sections, the competition between advertisers with conflicting preferences over news reports is always beneficial for informed consumers.

More generally, it is immediate to verify that when firms face uncorrelated shocks in the quality of their products, an increase in $L$ always increases the accuracy of news reports. That is, in the case of uncorrelated products, a higher degree of competition in the market for products always has a positive effect on the expected utility of informed consumers trough the media information channel. However, while in the uncorrelated case the effect of an increase in competition on accuracy of news is straightforward, when products' qualities are correlated this relationship becomes more complex. Specifically, in order to assess this issue it is first necessary to define a d.p.d. $\mathcal{P}^{\prime}$ over the $L+1$ products. That is, an increase in $L$ requires us to introduce a new distribution over the aggregate negative shocks in products' qualities. The following definition provides a characterization of $\mathcal{P}^{\prime}$ as an extension of $\mathcal{P}$ to $L+1$ products. 
Definition 2 (Extension to $L+1$ variables) Given a discrete probability distribution $\mathcal{P}$ over $L$ products (with expectation $1-\nu$ ), $\mathcal{P}^{\prime}$ extends $\mathcal{P}$ on $L+1$ products as follows:

$$
\begin{cases}p^{\prime}(0) & =\nu \cdot p(0) \\ p^{\prime}(I) & =(1-\nu) \cdot p(I-1)+\nu \cdot p(I) \quad \text { for } \quad 1 \leq I \leq L \\ p^{\prime}(L+1) & =(1-\nu) \cdot p(L)\end{cases}
$$

The above characterization of $\mathcal{P}^{\prime}$ ensures a proper comparison between the accuracy in presence of $L$ and $L+1$ products. ${ }^{30}$ Specifically, $\mathcal{P}^{\prime}$ satisfies two key conditions:

1. The expected fraction of bad quality products remains constant:

$$
\sum_{i=0}^{L+1} i p^{\prime}(i) \cdot \frac{1}{L+1}=\sum_{i=0}^{L} i p(i) \cdot \frac{1}{L}=(1-\nu)
$$

2. $\mathcal{P}^{\prime}$ is not more correlated than $\mathcal{P}$ above $\bar{D} \cdot{ }^{31}$

The first condition ensures that a randomly drawn product has the same probability of experiencing a negative shock in either scenario. Thus, the expected value of being uninformed remains constant when increasing the number of firms competing in the products market. The second condition is necessary to ensure that an increase in $L$ does not translate per se to higher incentives for the media outlet to hide negative information since, as pointed out by Corollary 1, a higher degree of correlation leads to a (weakly) lower accuracy of news reports. The following lemma characterizes the condition under which the accuracy of the media outlet's reports does not decrease when the competition in the market for products increases.

Lemma 2 Let $\bar{D}_{L}$ be defined as in (5) and $\varphi(L)=\bar{D}_{L} / L$ be the accuracy of the media outlet's reports in the presence of $L$ firms, with $\mathcal{P}$ being the d.p.d. over the L products' qualities. If one more producers enters in the market for products with $\mathcal{P}^{\prime}$ (defined by (6)) being the d.p.d. over the $L+1$ products' qualities, then $\varphi(L+1) \geq \varphi(L)$ if and only if:

$$
\begin{aligned}
(1-\nu) \theta \cdot \operatorname{Pr}\left(B_{\theta}\right. & \left.=\bar{D}_{L}\right)\left\{u_{g} \frac{E_{\mathcal{P}}\left[L-B \mid B_{\theta}=\bar{D}_{L}\right]}{L-\bar{D}_{L}}-1\right\} \\
& \geq \operatorname{Pr}\left(B_{\theta} \geq \bar{D}_{L}+1\right)\left\{1-u_{g} \frac{\nu}{L-\bar{D}_{L}}-u_{g} \frac{E_{\mathcal{P}}\left[L-B \mid B_{\theta} \geq \bar{D}_{L}+1\right]}{L-\bar{D}_{L}}\right\}
\end{aligned}
$$

\footnotetext{
${ }^{30}$ Notice that $\mathcal{P}^{\prime}$ extends $\mathcal{P}$ as if the additional product was independent from the existing $L$ products.

${ }^{31}$ See Definition 1 of "more correlated d.p.d.".
} 
That is, the above lemma provides a necessary and sufficient condition to ensure that a "marginal" increase in competition does not decrease the accuracy of news reports. Intuitively, an increase in the number of producers leads to an (at least proportional) increase in $\bar{D}$ if and only if the maximum amount of bad news that informed consumers would "tolerate" without deciding to not consume any of the products offered by the firms increases (at least proportionally). That is, an increase in competition in the market for products translates to higher accuracy of news reports if and only if the negative effect on informed consumers' beliefs (due to observing an additional bad signal) is offset by the positive effect due to the higher overall level of information. Specifically, $\bar{D}$ will increase if and only if informed consumers put a higher weight on the expectation that the additional bad news belongs to the additional product rather than on the expectation of the bad signal attaining to the $L$ products. Indeed, as pointed out by the following example, the above condition is not always satisfied. That is, an increase in the competition in the market for products may lead to a decrease in the accuracy of news reports and also in the expected utility of informed consumers.

Example (competition and accuracy) Let $L=3, \theta=1 / 2$ and let $\mathcal{P}$ be such that $p(1)=1 / 2, p(2)=1 / 15, p(3)=1 / 4$ (i.e., $\nu \simeq 0.54$ ). Then:

$$
\bar{D}_{L}= \begin{cases}0 & \text { if } u_{g} \in(\sim 1.86, \sim 1.89] \\ 1 & \text { if } u_{g} \in(\sim 1.89,8.5] \\ 2 & \text { if } u_{g} \in(8.5, \infty]\end{cases}
$$

Now let $L^{\prime}=4$ and consider the distribution $\mathcal{P}^{\prime}$ which extends $\mathcal{P}$ as defined by (6). Then:

$$
\bar{D}_{L^{\prime}}= \begin{cases}1 & \text { if } u_{g} \in(\sim 1.86, \sim 2.12] \\ 2 & \text { if } u_{g} \in(\sim 2.12, \sim 2.74] \\ 3 & \text { if } u_{g} \in(\sim 2.74, \infty]\end{cases}
$$

Hence, for example, given $u_{g}=2$ :

i) $\varphi\left(L^{\prime}\right)=\frac{1}{4}<\varphi(L)=\frac{1}{3}$.

ii) $E\left[U^{I}\left(L^{\prime}\right)\right] \simeq 1.257<E\left[U^{I}(L)\right] \simeq 1.261$.

That is, a marginal increase in product market competition may lead to a lower accuracy of news reports, a lower expected utility of informed consumers and, as a consequence, to a lower equilibrium fraction $\alpha$ of informed consumers (for any value of $c$ ).

Therefore, even though we have considered a "marginal" increase in competition by imposing that the extension of $\mathcal{P}$ to $L+1$ products does not increase the correlation among 
the existing products, it may still be the case that this higher degree of competition ends up not being beneficial for informed consumers. Indeed, by extending the distribution of $\mathcal{P}$ as if the additional product was independent from the existing $L$ products, we have focused on the most favorable scenario with respect to competition. Specifically, this is the situation where informed consumers may benefit the most from the positive effects of products market competition passing through the media information channel. Nevertheless, as shown by Lemma 2 and the above example, even in this case an increase in competition in the market for products does not necessarily lead to higher accuracy of news reports. Indeed, this increase in competition may actually lead to a decrease in the accuracy of news reports and to a lower expected utility of informed consumers. Therefore, while our analysis points out that competition among advertisers with conflicting preferences is beneficial for informed consumers and helps reduce "commercial media bias", when advertisers' products are correlated, a higher degree of competition

may actually lead advertisers and the media outlet to behave more "conservatively". That is, a higher degree of competition in the market for products may be associated with lower news accuracy and more "commercial media bias". In other words, while more competition among firms with conflicting preferences over news reports is beneficial for informed consumers, this may not be the case when firms share similar preferences over news contents.

\section{Robustness}

\subsection{Media outlet's private info}

In this section we discuss whether relaxing the assumption that the media outlet and producers share the same information (i.e., all observe $\mathbf{z}$ ) would affect our results on the equilibrium news reports of the media outlet (i.e., accuracy). In other words, when the media outlet has private information, could it earn higher profits by choosing different news reports with respect to the ones characterized in section 4 ?

Suppose that firm $l$ observes only the signal on its own product, $z_{l}$. Two features of the model immediately imply that the media outlet can never benefit from hiding an arbitrary subset of signals from an arbitrary subset of potential advertisers: 1) Information is hard, i.e., the media outlet can only make offers to advertisers contingent on the set of realized signals; 2) In equilibrium the media outlet cannot be paid by two (or more) advertisers who accepted offers involving conflicting messages. That is, in equilibrium the media outlet can only implement contracts that involve positive payments contingent on the message it will actually deliver. In other words, the media outlet can never 
"fool" advertisers and make them pay for a message that it will not send to its viewers. Therefore, by hiding any information from producers, the media outlet would simply restrict the set of contracts it could offer to them, since such contracts must be contingent on the vector of messages delivered and messages are hard information.

Thus, as shown by the following lemma, the media outlet is never able to earn profits which are higher than the ones it obtains in the case where it shares the same information as firms. That is, the strategy of fully disclosing its signals to potential advertisers always weakly dominates any partial disclosure strategy.

Lemma 3 By hiding any arbitrary subset of signals to producers at the bargaining stage, the media outlet is never able to earn a profit higher than the one it could obtain when revealing all its signals. Hence, disclosing all its signals to producers is a weakly dominant strategy for the media outlet.

The intuition behind this result is simple. The higher the number of bad signals observed by the media outlet, the (weakly) higher the profits it may extract from advertisers. Hence, since the higher the number of bad signal observed, the higher the "bargaining power" of the media outlet with respect to producers, the media outlet always has an incentive to disclose all of its signals to potential advertisers so it can maximize the adverting fees it can impose on them.

\subsection{Multiple Media Outlets}

This section discusses the robustness of our results to the presence of multiple media outlets (i.e., $N=2$ ). As in Besley and Prat (2006), we assume that both media outlets have the same information (i.e., they both observe $\mathbf{z}$ ), and that if at least one media outlet has informative news, then all media viewers become informed. That is, if at least one media outlet publishes a negative report on a firm's product, then every media viewer becomes informed of the bad quality of that product. ${ }^{32}$ Notice that, if different media outlets were to receive heterogenous information, increasing the number of media outlets would be beneficial per se. That is, by assuming that both media outlets have the same information, it is possible to study whether media pluralism by itself changes the informativeness of news reports. The following proposition provides a generalization of the results obtained in Proposition 1 to the case of multiple media outlets.

\footnotetext{
${ }^{32}$ This scenario is, for example, consistent with the empirical evidence found by Swinnen et al. (2005) regarding the case of the media coverage of the food dioxin crisis in 1999 in Belgium. The authors show that once a media outlet started publishing negative reports on this issue all the others quickly followed.
} 
Proposition 4 Let $D_{n_{i}} \leq B_{\theta}$ be the number of bad signals disclosed by media outlet $n_{i}$ in equilibrium given its news report $\mathbf{m}_{n_{i}}, \forall i=1,2$. Then, for $L=2$ and $N=2, \exists \bar{\rho}$, where $\bar{\rho}$ is given by (4), such that:

If $\rho<\bar{\rho}$, then $D_{n_{1}}=D_{n_{2}}=\min \left\{B_{\theta}, 1\right\}$ and $\alpha=\frac{u_{g}}{c} \cdot(1-\nu) \nu \theta \cdot(1-\rho)$. Moreover:

1. If $B_{\theta}=1$, then $\forall n_{i} \neq n_{j}, \Gamma_{n_{i}}=\alpha \frac{B_{\theta}}{4} ; \Gamma_{n_{j}}=0$

2. If $B_{\theta}=2$, then $\Gamma_{n_{1}}=\Gamma_{n_{2}}=\frac{\alpha}{2}$

If $\rho>\bar{\rho}$, then $D_{n_{1}}=D_{n_{2}}=0, \alpha=0$ and $\Gamma_{n_{1}}=\Gamma_{n_{2}}=0$.

From the consumers' perspective, the value of information remains the same as that characterized in the single media outlet case. Indeed, since for consumers the two media outlets are ex-ante identical, they all equally share the market for informed consumers. Hence, competition in the market for news does not increase the informativeness of news reports. ${ }^{33}$ On the other hand, the expected profits in the products and news markets are different with respect to the single media outlet case. Specifically, when only one media outlet is present in the market for news, it always has a monopoly power over information and it is always able to extract all the possible profits from advertisers. Instead, introducing competition in the market for news has a positive effect on the profits of "good" producers. Specifically, a firm producing a good quality product (or whose product media outlets have not discovered to be of bad quality), only needs to pay one of the media outlets to reveal the negative information about its rival's product. Hence, its bargaining power with respect to the single media outlet case increases. That is, it just needs to pay one media outlet an advertising fee equal to a $1 / 4$ of the total profits in the $\alpha$-market share of informed consumers (i.e., the maximum the bad quality firm is able to offer to each of the media outlets). Thus, good quality firms benefit from competition in the news market since "paying positive to go negative" becomes cheaper. Viceversa, the expected profits of a media outlet decrease more than proportionally with respect to the case when it did not face any competition in the market for news.

\section{Conclusions}

Consumers typically watch media for their entertainment and informational value. Such informational value also involves information regarding consumer products. Hence, the

\footnotetext{
${ }^{33}$ Clearly, as shown by Germano and Meier (2010), if media outlets could, instead, increase their audience share by increasing the accuracy of their news reports (i.e., media outlets committing to a given accuracy level), then competition in the market for news may also increase the expected accuracy of news reports. Moreover, if there were a transaction cost between advertisers and media outlets (as in Besley and Prat, 2006), there may be a threshold in the number of media outlets above which firms with a bad quality product would not have enough resources to "silence" all media outlets.
} 
information supplied by media will ultimately affect the purchasing decisions of consumers. Since producers are also potential advertisers, there may be a subtle relationship between news and advertising. Specifically, adverting fees may represent a form of hidden transfer to the media to hide negative information about the advertiser's own product (paying positive to avoid negative) or to disclose negative information about the competitors' products (paying positive to go negative). We have shown that whether or not advertisers' pressure on media has negative consequences on the accuracy of media reports ultimately depends on whether the competition in the products' market also translates into competition over media contents. In turn, the extent of competition over media contents depends on the degree of correlation among firms' products. When the correlation in products' qualities is high, all firms share the same preferences over media reports (i.e., every firm wants media to refrain from disclosing any negative information about any product since such news would hurt the sales of its own product). Hence, in this case, advertisers compete in the market for products but they do not compete over media reports. Instead, when this correlation is low, firms have conflicting preferences over media contents (i.e., "bad" firms want to pay positive to avoid negative and "good" firms want to pay positive to go negative). Hence, advertisers compete both in the products market and over media contents. Therefore, our results suggests that we should observe media to report more accurate information (i.e., disclose relatively more "bad news") on products belonging to industries where the correlation among firms' products is lower. Moreover, the analysis shows that the effect of competition in the market for products on the accuracy of news reports is not univocal. Specifically, when advertisers' products are uncorrelated, a higher degree of competition in the market for products is always associated with a higher accuracy of media outlet's reports. Instead, this is not necessarily true when products are correlated. That is, it may be the case that an increase in the number of firms competing in the products market leads to lower news accuracy due to the fact that an increase in the number of producers does not translate in more bad news disclosed to informed consumers. In other words, while when potential advertisers have conflicting preferences over news reports, competition is beneficial for informed consumers, this may not be the case when potential advertisers share similar preferences over news contents. More generally, our analysis suggests that "commercial media bias" represents a serious concern in presence of a high degree of correlation among advertisers' products. Instead, when advertisers' products are weakly correlated, "commercial media bias" is endogenously swept away by the advertisers' competition over news contents. Therefore, media regulators should target their monitoring efforts towards news contents/issues upon which advertisers are likely to share similar preferences. Finally, while the analysis has focused on a symmetric setting to isolate the model from $a d-h o c$ 
effects, future research should probably explore the role of asymmetries among advertisers. That is, exogenous differences in the willingness to pay of different advertisers may have important consequences on the information received by consumers.

\section{References}

[1] Anderson, S. P., and Gabszewicz J. J. (2006) "The Media and Advertising: a tale of twosided markets". In V. Ginsburgh and D. Throsby (Eds), Handbook of Cultural Economics, Elsevier Science.

[2] Armstrong, M. (2006) "Competition in Two-Sided Markets" Rand Journal of Economics, Vol. 37, No. 3, 668-691.

[3] Armstrong, M. and Weeds, H. (2007) "Programme Quality in Subscription and AdvertisingFunded Television", mimeo, UCL and University of Essex.

[4] Bagwell, K. (2007). "The economic analysis of advertising". In M. Armstrong and R. Porter (Eds.), Handbook of industrial organization, 3, 1701-1844. Amsterdam, North Holland.

[5] Bagdikian, B.H. (2004) The New Media Monopoly, Beacon Press, Boston

[6] Baker, C.E. (1994) Advertising and a Democratic Press, Princeton University Press, Princeton, NJ.

[7] Bergemann, D., and Bonatti A., (2010), "Targeting in Advertising Markets: Implications of Offline vs. Online Media", Cowles Foundation Discussion Paper 1758, Yale University.

[8] Besley T., and Prat A. (2006) "Handcuffs for the grabbing hand? Media capture and government accountability", American Economic Review, 96(3): 720-736.

[9] Blasco, A., and Sobbrio, F., (2011) "Competition and Commercial Media Bias", DSE Working Paper 767, University of Bologna

[10] Boykoff, M.T. (2007) "Flogging a dead norm? Newspaper coverage of anthropogenic climate change in the United States and United Kingdom from 2003 to 2006", Area, 39 (2), $470-481$.

[11] Boykoff, M.T., and Boykoff, J.,M. (2004) "Balance as Bias: Global Warming and the US Prestige Press", Global Environmental Change, 14, 125-136.

[12] Butters, G. (1977) "Equilibrium Distributions of Sales and Advertising Prices," Review of Economic Studies, 44, 465-491.

[13] Chaloupka, F.J., and Warner K., E. (2000) "The Economics of Smoking". In A.J. Culyer and J.P. Newhouse (Eds), Handbook of Health Economics, 1, 1541-1627. Elsevier Science.

[14] Chen, Y., and Riordan, M., H. (2007) "Price and Variety in the Spokes Model", Economic Journal, 117, 897-921.

[15] Dewatripont, M. and Tirole, J. (1999) "Advocates", Journal of Political Economy, 107(1): $1-39$.

[16] Di Tella, R., and Franceschelli, I. (2009). "Government Advertising and Media Coverage of Corruption Scandals" NBER working paper no. 15402 
[17] Downs, A., (1957), An Economic Theory of Democracy, New York, Harper.

[18] Dukes, A., J. (2004) "The Advertising Market in a Product Oligopoly." Journal of Industrial Economics, 52(3): 327-348

[19] Dyer, O., (2004) "Journal rejects article after objections from marketing department", British Medical Journal, 328: 224.

[20] Ellman, M. and Germano, F. (2009) "What do the Papers Sell? A Model of Advertising and Media Bias", Economic Journal, 119: 680-704.

[21] Fletcher, R. H., (2003) "Adverts in medical journals: caveat lector", The Lancet, 361: $10-11$.

[22] Fugh-Berman, A., Alladin, K., and Chow, J., (2006) "Advertising in Medical Journals: Should Current Practices Change?", PLoS Med, 3(6): 762-768.

[23] Gal-Or , E., Geylani, T., and Yildirim, T., P., (2010) "The Impact of Advertising on Media Bias", mimeo, University of Pittsburgh.

[24] Gambaro, M., and Puglisi, R. (2009) "What do ads buy? Daily coverage of listed companies on the Italian press", EUI Working Paper RSCAS 2010/26.

[25] George, L. and Waldfogel, L. (2003) "Who affects whom in daily newspaper markets?", Journal of Political Economy, vol. 111(4), 765-85.

[26] Germano, F. (2009) "On Commercial Media Bias", Working Paper 1133, Universitat Pompeu Fabra

[27] Germano, F., and Meier, M., (2010) "Concentration and self-censorship in commercial media", Working Paper 1256, Universitat Pompeu Fabra

[28] Gabszewicz, J., Laussel, D., and Sonnac, N. (2001) "Press Advertising and the ascent of the 'Pensee Unique", European Economic Review, 45:641-651.

[29] Gabszewicz, J., Laussel, D., and Sonnac, N. (2002) "Press Advertising and Political Differentiation of Newspapers", Journal of Public Economic Theory, 317-334.

[30] Gentzkow, M., Glaeser, E., L., and Goldin, C., (2006) "The Rise of the Fourth Estate: How Newspapers Became Informative and Why it Mattered". In Glaeser, E., and Goldin C., (Eds), Corruption and Reform: Lessons from America's Economic History. NBER/University of Chicago Press.

[31] Grossman, G., and Shapiro, C. (1984) "Informative Advertising with Differentiated Products" Review of Economic Studies, 51, 63-81.

[32] Hamilton, J., T. (2004) All The News That's Fit to Sell: How the Market Transforms Information into News, Princeton University Press.

[33] Milgrom, P. (1981) "Good News and Bad News: Representation Theorems and Applications", Bell Journal of Economics, 12, 380-391.

[34] Milgrom, P., and Roberts J. (1986) "Prices and Advertising Signals of Product Quality." Journal of Political Economy, 94, 796-821.

[35] Nelson, P. (1974). Advertising as information. Journal of Political Economy, 82, 729-754. 
[36] Oreskes, N. (2004) "Beyond the Ivory Tower: The Scientific Consensus on Climate Change" Science, 306, 1686-1686.

[37] Oreskes, N., and Conway, E., (2010) Merchants of Doubts, Bloomsbury Press.

[38] Petrova, M. (2010) "Newspapers and Parties: How Advertising Revenues Created an Independent Press", mimeo, New Economic School.

[39] Petrova, M. (2011) "Mass Media and Special Interest Groups", mimeo, New Economic School.

[40] Poitras, M., and Sutter, D., (2009) "Advertiser pressure and control of the news: The decline of muckraking revisited", Journal of Economic Behavior 83 Organization, 72: 944958.

[41] Rasmussen, E., and E. Petrakis (1992) "Defining the Mean-Preserving Spread: 3-pt versus 4-pt" in Decision Making Under Risk and Uncertainty: New Models and Empirical Findings, editor J. Geweke for Kluwer, Amsterdam.

[42] Reuter, J., and Zitzewitz E. (2006) "Do Ads Influence Editors? Advertising and Bias in the Financial Media", Quarterly Journal of Economics, 121, 197-227.

[43] Reuter, J., (2009) "Does Advertising Bias Product Reviews? An Analysis of Wine Ratings", Journal of Wine Economics, 4(2), 125-151.

[44] Rinallo, D., and Basuroy, S., (2009) "Does Advertising Spending Influence Media Coverage of the Advertiser?", Journal of Marketing, 73(6), 33-46.

[45] Roger, G., (2010) "Two-sided competition and differentiation (with an application to media)", School of Economics Discussion Paper 2010/27, University of New South Wales.

[46] Segal, I., (1999) "Contracting With Externalities*", Quarterly Journal of Economics 114(2), 337-388.

[47] Strömberg, D. (2004) "Mass Media Competition, Political Competition, and Public Policy", Review of Economic Studies, 71(1), 265-284.

[48] Swinnen, J., F., M., McCluskey, J., and Francken, N. (2005) "Food safety, the media, and the information market", Agricultural Economics, 32(1), 175-188

\section{Appendix A}

In this Appendix we include some technical specifications on the assumptions we are making on the equilibrium, and on the partial ordering we use to rank correlation between different probability distributions.

Definition A (Equilibrium of the game) A subgame perfect Bayesian-Nash equilibrium of the game consists of a fraction of informed consumers $\alpha^{*}$, a sequence of media outlet's offers $\left\{\tau_{l}^{*}\right\}_{l \in \mathcal{L}}$, firms decisions $\left\{a_{l}^{*}\right\}_{l \in \mathcal{L}}$ and a media outlet's news report $\mathbf{m}^{*}$, such that:

1. Consumers maximize their expected utility given their rational expectations over $\left\{\tau_{l}^{*}\right\}_{l \in \mathcal{L}}$, $\left\{a_{l}^{*}\right\}_{l \in \mathcal{L}}$ and $\mathbf{m}^{*}:$

$$
\alpha^{*}=\frac{E_{\mathcal{P}}\left[U^{I}\left(\mathbf{m}^{*}\right)\right]-\nu \cdot u_{g}}{c}
$$


2. Every producer maximizes its profits given $\left\{\tau_{l}^{*}\right\}_{l \in \mathcal{L}}$ :

$$
a_{l}^{*} \in \underset{a_{l} \in \mathbb{A}}{\arg \max } \Pi_{l}=S_{l}\left(\mathbf{m}^{*}\left(a_{l}, a_{-l}^{*}\right), \alpha^{*}\right)-\tau_{l}\left(\mathbf{m}^{*}\left(a_{l}, a_{-l}^{*}\right), a_{l}\right), \quad \forall \alpha^{*} \geq 0 .
$$

This is well defined because $S_{l}(\mathbf{m}, \alpha)$ is linear in $\alpha$, and it is assumed that for $\alpha=0$ producers behave as if $\alpha>0 .{ }^{34}$

3. For every $\alpha^{*} \geq 0$, the media outlet maximizes its profits given $\alpha^{*}$ and $\left\{a_{l}^{*}\right\}_{l \in \mathcal{L}}$ :

$$
\left\{\left\{\tau_{l}^{*}\right\}_{l \in \mathcal{L}}, \mathbf{m}^{*}\right\} \in \underset{\tau_{l} \in \mathcal{C} ; \mathbf{m} \in \mathcal{M}}{\arg \max } \Gamma(\mathbf{m}, \tau, \mathbf{a})=\sum_{l \in \mathcal{L}} \tau_{l}\left(\mathbf{m}, a_{l}^{*}\right)
$$

where $\mathcal{M}$ is the set of any $\mathbf{m}$ consistent with the information $\mathbf{z}$ obtained by the media, i.e. $z(l)=\varnothing \Rightarrow m(l)=\varnothing$ for any firm $l$.

Notice that, given the common prior beliefs $\mathcal{P}$, the definition of the equilibrium of the game involves a subgame perfect Bayes-Nash equilibrium since informed consumers are bayesian and update their beliefs on products' qualities given the news $\mathbf{m}^{*}$ reported by the media outlet. Moreover, in the robustness case discussed in section 7.1, firms update their beliefs given the media outlet's offers $\left\{\tau_{l}^{*}\right\}$. However, as shown by Lemma 3, in this case the media outlet has no incentive to hide information from potential advertisers. Thus, even in this case all firms end up observing z. Hence, we can disregard out-of-equilibrium beliefs.

We conclude this appendix with an example and a lemma that are related to Definition 1.

Example (3-pt mean preserving spread) For any $1 \leq \bar{D} \leq L-1$, such that $q(\bar{D})>0$, it is possible to construct $P$ that is more correlated than $Q$ above $\bar{D}$, applying a $3-$ pt mean preserving spread, as defined in Rasmussen and Petrakis (1992). We define $p(0) \equiv q(1)+\frac{L-\bar{D}}{L} \cdot q(\bar{D}), p(\bar{D}) \equiv 0, p(L) \equiv q(L)+\frac{\bar{D}}{L} \cdot q(\bar{D})$, while $p(I) \equiv q(I)$ for any other $I \notin\{1, \bar{D}, L\}$. It is easy to check that $P$ and $Q$ have the same expectation, and that $P$ is more correlated than $Q$ above $\bar{D}$.

The above example shows that Definition 1 is consistent with a smooth mean-preserving spread, as it spreads more probability weight on the right-tail of the distribution. Finally, we have a lemma.

Lemma A Consider two discrete probability distributions $\mathcal{P}$ and $\mathcal{Q}$, on $L$ events, such that they have the same expectation $\nu$, such that $\mathcal{P}$ is more correlated than $\mathcal{Q}$ above $H$. We have that for every $H \leq k \leq L-1$, and for any function $\phi(I, k)$ from $I, k \in\{H, \ldots, L\}, I \geq k$, which is positive valued, the following inequality holds:

$$
\frac{\sum_{I=k}^{L} I \cdot p(I) \phi(I, k)}{\sum_{J=k}^{L} p(J) \phi(J, k)} \geq \frac{\sum_{I=k}^{L} I \cdot q(I) \phi(I, k)}{\sum_{J=k}^{L} q(J) \phi(J, k)} .
$$

Proof. The inequality is equivalent to

$$
\sum_{I=k}^{L} \sum_{J=k}^{L} I p(I) \phi(I, k) q(J) \phi(J, k) \geq \sum_{I=k}^{L} \sum_{J=k}^{L} J p(I) \phi(I, k) q(J) \phi(J, k) .
$$

We proceed by backward induction on $k$.

First Step of the Induction: The statement holds with equality if $k=L$.

\footnotetext{
${ }^{34}$ This is without loss of generality, because if $\alpha=0$, every equilibrium will be characterized by the same null transfers.
} 
Induction Hypothesis: Now suppose that the inequality holds for some $H+1 \leq k+1 \leq L$, that is

$$
\sum_{I=k+1}^{L} \sum_{J=k+1}^{L} I p(I) \phi(I, k+1) q(J) \phi(J, k+1) \geq \sum_{I=k+1}^{L} \sum_{J=k+1}^{L} J p(I) \phi(I, k+1) q(J) \phi(J, k+1)
$$

for any function $\phi(I, k)$ which is positive valued.

Induction Step: we must prove the result for $k$. The inequality (a) is equivalent to

$$
\begin{aligned}
& \left(\sum_{I=k+1}^{L} \sum_{J=k+1}^{L} I p(I) \phi(I, k) q(J) \phi(J, k)\right)+k \cdot p(k) q(k) \phi(k, k)^{2} \\
& +\left(\sum_{I=k+1}^{L} k p(k) \phi(k, k) q(I) \phi(I, k)+I p(I) \phi(I, k) q(k) \phi(k, k)\right) \\
& \geq\left(\sum_{I=k+1}^{L} \sum_{J=k+1}^{L} J p(I) \phi(I, k) q(J) \phi(J, k)\right)+k \cdot p(k) q(k) \phi(k, k)^{2} \\
& +\left(\sum_{I=k+1}^{L} I p(k) \phi(k, k) q(I) \phi(I, k)+k p(I) \phi(I, k) q(k) \phi(k, k)\right) .
\end{aligned}
$$

The first term in parenthesis in the 1.h.s. of the inequality is greater than the first term in parenthesis in the r.h.s., because the induction hypothesis holds for any $\phi(I, k)$, and we can define a new function $\phi^{\prime}(I, k)$ such that $\phi^{\prime}(I, k+1) \equiv \phi(I, k)$, for any $I>k$.

The second term in both sides is the same.

Therefore, the whole inequality in (b) holds if for every $I \in\{k+1, \ldots, L\}$ we have

$$
\begin{aligned}
& I(p(I) \phi(I, k) q(k) \phi(k, k)-p(k) \phi(k, k) q(I) \phi(I, k)) \\
& \geq k(p(I) \phi(I, k) q(k) \phi(k, k)-p(k) \phi(k, k) q(I) \phi(I, k)) .
\end{aligned}
$$

We have that $I>k$, and that

$$
p(I) \phi(I, k) q(k) \phi(k, k) \geq p(k) \phi(k, k) q(I) \phi(I, k),
$$

because

$$
\frac{p(I) \phi(I, k) q(k) \phi(k, k)}{p(k) \phi(k, k) q(I) \phi(I, k)}=\frac{p(I) q(k)}{p(k) q(I)} \geq 1
$$

as $\mathcal{P}$ is more correlated than $\mathcal{Q}$ above $H$ and so $\frac{p(I)}{q(I)} \geq \frac{p(k)}{q(k)}$ for every $I>k$ (this is just an iterated application of the definition).

This closes the proof by induction and proves the statement. Q.E.D.

\section{Appendix B}

\section{Proof of Proposition 1.}

Let us prove first the uncorrelated case (Result 1) and then we extend to the correlated case.

If negative shocks are uncorrelated and $\alpha>0$, informed consumers will randomly purchase among products without bad news, i.e., $m_{l}=\varnothing$, because it is always the case that $E_{\mathcal{P}}\left(u\left(q_{l}\right) \mid m_{l}=\right.$ 
$\varnothing) \geq \nu u_{g}$. Hence, producer l's total sales are:

$$
S_{l}(D)=\frac{(1-\alpha)}{2}+\mathbf{1}_{m_{l}=\varnothing} \cdot \frac{\alpha}{2-D}
$$

where $\mathbf{1}_{m_{l}=\varnothing}$ is an indicator function. Clearly, such sales depend on the news reported by the media outlet, i.e., $\mathbf{m}$, and therefore, upon $\mathbf{z}$. Let us consider separately each possible signal realization:

i) First, consider $z_{1}=z_{2}=\varnothing$, i.e., $B_{\theta}=0$. In this, trivial, case the media outlet cannot do anything else than reporting $D=0$ and so, it cannot ask any positive transfer to the advertisers, e.g., $t_{1}=t_{2}=0$.

ii) Then, consider $z_{1}=z_{2}=b$, i.e., $B_{\theta}=2$. The media outlet has now a richer space of possible reports: $\mathcal{M}=\{(\varnothing, \varnothing),(\varnothing, b),(b, \varnothing),(b, b)\}$. Moreover, since the products are uncorrelated and given the tie-breaking rule, it does not have any incentive to conceal any negative information about a producer that rejects its own offer. Therefore, producer l's sales are $(1-\alpha) / 2$, conditional upon rejecting the offer. Hence, each producer will accept any offer such that:

$$
\tau_{l}(\mathbf{m}, a) \leq \mathbf{1}_{m_{l}=\varnothing} \frac{\alpha}{2-D}
$$

Clearly, the media outlet would set the highest possible ad fee which is consistent with (d), i.e., the inequality is strict. Note that, the media outlet could now either disclose both signals, earning $t_{1}=t_{2}=\alpha / 2$ from both producers, or just one signal, earning either $t_{1}=\alpha$ and $t_{2}=0$ or viceversa. However, given the tie-breaking rule, the media outlet prefers the latter option which is the most informative to consumers.

Finally, the contract offered is an equilibrium because it allows the media outlet to earn all the revenues from the market of informed consumers, i.e., $\Gamma=\alpha$. This clearly represents an upper bound to all possible media outlet's profits.

iii) Now consider the case where $z_{1}=\varnothing$ and $z_{2}=b$ (the case where $z_{1}=b$ and $z_{2}=\varnothing$ is clearly symmetric), i.e., $B_{\theta}=1$. Again, the media outlet may present a contract for the bad producer such that $(\mathrm{d})$ is strict. Given the bad producer will accept, the best response for the good producer is to accept any offer such that:

$$
\tau_{l}(\mathbf{m}, a) \leq \frac{\alpha}{2-D}-\frac{\alpha}{2} .
$$

At equilibrium (e) is strict as well. Therefore, if $D=0$, the media outlet earns $t_{1}=0$ and $t_{2}=\alpha / 2$, whereas, if $D=1$, the media outlet earns $t_{1}=\alpha / 2$ and $t_{2}=0$. Thus, because of the tie breaking rule, the single bad signal is revealed and just one payment is due. In this case the media earns $\Gamma=\frac{\alpha}{2}$, which is again an upper bound.

Summing up $i$ ), ii) and $i i i$ ), we obtain the media outlet's equilibrium reporting strategy in the uncorrelated case. Specifically, $D^{*}=\min \left\{B_{\theta}, 1\right\}$.

Let us now prove by contradiction that when shocks are correlated the reporting strategy is different from the one of the uncorrelated shocks case. Suppose that the media outlet were adopting the same disclosure strategy as in Result 1 . Since $D$ is the number of bad signals disclosed by the media outlet given its message $\mathbf{m}$, we can rewrite the utility functions of the informed consumers as a function of $D$. Specifically, conditional upon observing $D=1$, the expected utility of an informed consumers is:

$$
E\left[U^{I} \mid D=1\right]=\max \left\{u_{g} \cdot \frac{p(1)}{p(1)+p(2)(2-\theta)} ; u_{0}\right\}
$$


By using the definition of the coefficient of correlation among two negative shocks, we have that: $\nu(1-\nu) \rho=p(2)-(1-\nu)^{2}$, together with the definition of the mean: $p(1)+2 p(2)=2(1-\nu)$, we obtain that a consumer purchase the good if:

$$
\rho \leq \bar{\rho} \equiv \frac{2\left(u_{g} \nu-1\right)+\theta(1-\nu)}{\nu\left(2 u_{g}-\theta\right)}
$$

Hence, if $\rho>\bar{\rho}$, informed consumers would not purchase any product whenever $D>0$. Therefore, if correlation is high, the same disclosure strategy as in Result 1 is not an equilibrium. In this case, the media outlet will instead hide all signals. Indeed, it may ask a tariff $t_{1}=t_{2}=\frac{\alpha}{2}$ to each producer. Thus, there will be two symmetric equilibria where only one of the two producers will accept the media outlet offer and all signals are concealed. Thus, the media outlet's equilibrium strategy in both cases will be:

$$
D^{*}= \begin{cases}\min \left\{B_{\theta}, 1\right\} & \text { if } \rho<\bar{\rho} \\ 0 & \text { if } \rho \geq \bar{\rho} .\end{cases}
$$

\section{Q.E.D.}

\section{Proof of Proposition 2}

Also in this case, let us prove first the uncorrelated case (Result 2) and then we extend to the correlated case.

When shocks are uncorrelated, there are two possible cases:

i) First, suppose that $B_{\theta}=L$. The media outlet will offer a contract: $\tau_{l}(\mathbf{m}, a)=\mathbf{1}_{m_{l}=\varnothing} \cdot \frac{\alpha}{L-D}$. Specifically, this specifies an ad fee, i.e., $t_{l}=\frac{\alpha}{L-D}$, to be paid contingent on $a$ ) concealing the bad news about firm $l$ 's product and $b$ ) disclosing bad news about other $D$ products. It is a (weakly) dominant strategy for any producer to accept the offer. And so, the media outlet will receive the same payment for every $D \in\{0, L-1\}$ disclosed. However, given the tie-breaking rule, the media outlet will choose $D^{*}=L-1$.

ii) Second, suppose that $B_{\theta}<L$. Bad producers will still accept the above offer, whereas good producers are asked $\tau_{l}(\mathbf{m}, a)=\frac{\alpha}{L-D}-\frac{\alpha}{L}$; that is, an ad fee is paid contingent on the number $D$ of bad signals disclosed. In this case, the media outlet may earn an equal transfer from both either "good" or "bad" firms and so, it will choose $D^{*}=B_{\theta}$.

Summing up $i$ ) and $i i$ ) we obtain the stated result.

Let's now consider the case of correlated shocks. As a first step, suppose that the optimal disclosure strategy for the media outlet is: $D^{*}=\min \left\{B_{\theta} ; \hat{D}\right\}$ with $\hat{D}>0$. Clearly, $\hat{D}$ must be such that each informed consumers is willing to choose one of the products offered by firms not subject to such bad news. i.e., such that $m_{l}=\varnothing$. Whereby the gross profits are as in equation (c). Note that this will be true for all $D \leq \hat{D}$.

Let us consider separately each possible signals realization:

1. If $B_{\theta} \leq \hat{D}$, then all results in the uncorrelated case extend to this case and the media outlet reveals $D=B_{\theta}$ earning $\Gamma=B \frac{\alpha}{L}$.

2. If $B_{\theta}>\hat{D}$, then $B_{\theta}-\hat{D}$ bad signals would be concealed. In this case, to maximize ad fees, the media outlet may offer a contract to each of the bad quality producers offering to conceal the signal about their own quality, i.e., $\tau_{l}(\mathbf{m}, a)=\mathbf{1}_{m_{l}=\varnothing} \frac{\alpha}{L-\hat{D}}$. Whereas, the offer to good quality producers may be: $\tau_{l}(\mathbf{m}, a)=\frac{\alpha}{L-D}-\frac{\alpha}{L}$. 
Clearly, if $\hat{D}=L-1$, all producers are of bad quality and they will compete to be the only firm in the market of informed consumers. In all other cases, however, if a bad producer rejects the offer, it is still possible that its own signal is concealed because some good producer and / or a less than $\hat{D}$ number of other bad producers have accepted the offer from the media outlet. However, the media outlet may (credibly) publicly announce that, when it is indifferent in terms of ad fees between reporting bad signals about two firms, e.g., $l$ and $l^{\prime}$, the media outlet will report always the signal concerning firm $l>l^{\prime}$. At this point, it becomes a unique equilibrium for the last firm in this "list" to accept the offer. If not, the signal is revealed with probability one. Then, given that this firm accepted the offer, the second producer from the end will accept as well, and by induction, this process iterates to all the other bad quality firms.

Finally, given that all bad firms accepted the offer, the good firms will accept as well. Therefore, the media outlet receives a sum of transfers from the set of good firms along with the transfers from the bad producers who accepted the offer and whose signal has been concealed, and this sum must be equal to the transfers that the media outlet could obtain from all bad firms by hiding all signals:

$$
\begin{gathered}
\frac{\alpha(L-\hat{D})}{L-\hat{D}}-\frac{\alpha\left(L-B_{\theta}\right)}{L} \geq \frac{\alpha B_{\theta}}{L} \\
\frac{\alpha B_{\theta}}{L} \geq \frac{\alpha B_{\theta}}{L}
\end{gathered}
$$

At this point, the media outlet earns $\Gamma=\frac{\alpha B_{\theta}}{L}$ and reveal $D^{*}=\hat{D}$. Hence to complete the proof for the case $\bar{D}>0$, we must specifies a value of $\hat{D}$, denoted $\bar{D}$, which maximizes the media outlet's profits. Therefore, at equilibrium, it must be true that $\bar{D}$ is defined as in the proposition. Finally, when $\bar{D}=0$ and the media outlet observes $B_{\theta} \geq 1$, it may ask to every firm an ads fee $\tau_{l}(\mathbf{m}, a)=\frac{\alpha}{L}$ contingent on reporting $D^{*}=0$. Thus, there will be $L$ symmetric equilibria where only one of the $L$ producers will accept the media outlet offer. Specifically, the media outlet will earn $\frac{\alpha}{L}$ and its equilibrium strategy will be $D^{*}=0 . \quad$ Q.E.D.

\section{Proof of Corollary 1}

By the definition of $\bar{D} \equiv \bar{D}(\mathcal{P})$ we have that

$$
u_{g} \cdot \frac{L-E_{\mathcal{P}}[B \mid \bar{D}(\mathcal{P})]}{L-\bar{D}(\mathcal{P})} \geq \nu \cdot u_{g}
$$

Therefore, a necessary condition to have $\bar{D}(\mathcal{Q})>\bar{D}$ is that:

$$
\frac{L-E_{\mathcal{P}}[B \mid \bar{D}]}{L-\bar{D}}>\frac{L-E_{\mathcal{Q}}[B \mid \bar{D}]}{L-\bar{D}}
$$

which is equivalent to:

$$
E_{\mathcal{P}}\left[B \mid B_{\theta} \geq \bar{D}\right]<E_{\mathcal{Q}}\left[B \mid B_{\theta} \geq \bar{D}\right]
$$

Then, we can apply Lemma A in Appendix A, labelling $\phi(I, k) \equiv \sum_{i=k}^{I}\left(\begin{array}{l}I \\ i\end{array}\right) \theta^{i}(1-\theta)^{I-i}$ which is positive valued, and $H=\bar{D}$. Hence, it follows immediately that the above inequality is always verified when $\mathcal{P}$ is more correlated than $\mathcal{Q}$ above $\bar{D}$. $\quad$ Q.E.D.

\section{Proof of Lemma 1}

Let's start with the case where $\rho=0$. Then, the expected utility of an informed consumers who 
accessed the media outlet's report depends on $D^{*}$. This can be either

$$
E\left[U^{I} \mid D^{*}=1\right]=u_{g} \cdot \frac{\operatorname{Pr}\left(B=1 \cap B_{\theta} \geq 1\right)}{\operatorname{Pr}\left(B_{\theta} \geq 1\right)}
$$

or:

$$
E\left[U^{I} \mid D^{*}=0\right]=u_{g} \cdot \frac{\operatorname{Pr}\left(B=0 \cap B_{\theta}=0\right)}{\operatorname{Pr}\left(B_{\theta}=0\right)}+\frac{u_{g}}{2} \cdot \frac{\operatorname{Pr}\left(B=1 \cap B_{\theta}=0\right)}{\operatorname{Pr}\left(B_{\theta}=0\right)}
$$

Because of independence, we have: $p(0)=\nu^{2}, p(1)=2 \nu(1-\nu)$. Thus, the ex ante expected value from being informed is:

$$
E\left[U^{I}\right]=u_{g}\left[\nu^{2}+\nu(1-\nu)(1+\theta)\right]
$$

Finally, the equilibrium fraction of informed consumers is:

$$
\alpha=\frac{E\left[U^{I}\right]-E\left[U^{U}\right]}{c}=\frac{u_{g} \cdot \nu(1-\nu) \theta}{c}
$$

Now we can generalize the above. For $\rho \leq \bar{\rho}$, the ex ante expected utility of being informed for consumers:

$$
\begin{aligned}
E\left[U^{I}\right] & =u_{g} \cdot\left[p(0)+p(1) \frac{1+\theta}{2}\right] \\
& =u_{g} \cdot\left[1-p(1) \frac{1-\theta}{2}-p(2)\right]
\end{aligned}
$$

where $\frac{p(1)}{2}=(1-\nu)-p(2)$ and $p(2)=\rho \cdot \nu(1-\nu)+(1-\nu)^{2}$. Hence:

$$
\begin{aligned}
E\left[U^{I}\right] & =u_{g} \cdot\left[1-(1-\nu)(1-\theta)-\rho \cdot \nu(1-\nu) \theta-(1-\nu)^{2} \theta\right] \\
& =u_{g} \cdot[1-(1-\nu)[1+\theta(1-\nu(1-\rho))]
\end{aligned}
$$

Finally, the equilibrium fraction of viewers is:

$$
\alpha=\frac{u_{g}}{c} \cdot(1-\nu) \nu \theta \cdot(1-\rho)
$$

Instead, clearly for $\rho>\bar{\rho}, \alpha=0$. Q.E.D.

\section{Proof of Proposition 3}

First of all, we need to derive the equilibrium fraction of informed consumers for the case of an arbitrary number of firms, i.e., $L \geq 2$. Let's start with the uncorrelated case. A viewer's expected value from being informed is:

$$
\begin{aligned}
E\left[U^{I}\right] & =u_{g} \cdot \max \left\{\operatorname{Pr}\left(q_{l}=q \mid z_{l}=\varnothing\right) \cdot \operatorname{Pr}\left(B_{\theta}<L\right), \nu\right\} \\
& =u_{g} \cdot \operatorname{Pr}\left(q_{l}=q \mid z_{l}=\varnothing\right) \cdot \operatorname{Pr}\left(B_{\theta}<L\right) \\
& =u_{g} \cdot \frac{\nu}{1-\theta(1-\nu)} \cdot\left(1-(1-\nu)^{L} \theta^{L}\right)
\end{aligned}
$$

Thus, the equilibrium fraction of viewers is:

$$
\begin{aligned}
\alpha & =\nu u_{g} \cdot \frac{\theta(1-\nu)\left(1-(1-\nu)^{L-1} \theta^{L-1}\right)}{1-\theta(1-\nu)} \\
& =\nu u_{g} \cdot \sum_{l=1}^{L-1}(1-\nu)^{l} \theta^{l}
\end{aligned}
$$


In the correlated case, the expected utility from being informed is:

$$
\begin{aligned}
E\left[U^{I}\right]= & u_{g} \cdot \max \left\{\sum_{B_{\theta}=0}^{\bar{D}-1} \operatorname{Pr}\left(q_{l}=g \mid B_{\theta}\right) \cdot \operatorname{Pr}\left(B_{\theta}\right)+u_{g} \cdot \operatorname{Pr}\left(q_{l}=g \mid \bar{D}\right) \cdot \operatorname{Pr}\left(B_{\theta} \geq \bar{D}\right), \nu\right\} \\
= & u_{g} \cdot \max \left\{\left[\sum_{B_{\theta}=0}^{\bar{D}-1} \sum_{l=B_{\theta}}^{L} p(l) \cdot\left(\begin{array}{c}
l \\
B_{\theta}
\end{array}\right) \theta^{B_{\theta}}(1-\theta)^{l-B_{\theta}} \cdot \frac{L-l}{L-B_{\theta}}+\right.\right. \\
& \left.\left.+\sum_{l=\bar{D}}^{L} p(l) \cdot \sum_{j=\bar{D}}^{l}\left(\begin{array}{l}
l \\
j
\end{array}\right) \theta^{j}(1-\theta)^{l-j} \cdot \frac{L-l}{L-\bar{D}}\right], \nu\right\}
\end{aligned}
$$

hence

$$
\alpha=\frac{u_{g}}{c} \max \left\{\left[\sum_{B_{\theta}=0}^{\bar{D}-1} \sum_{l=B_{\theta}}^{L} p(l) \cdot \phi\left(l ; B_{\theta}, \theta\right) \cdot \frac{L-l}{L-B_{\theta}}+\sum_{l=\bar{D}}^{L} p(l) \cdot \sum_{j=\bar{D}}^{l} \phi(l ; j, \theta) \cdot \frac{L-l}{L-\bar{D}}-\nu\right], 0\right\}
$$

where $\phi\left(l ; B_{\theta}, \theta\right)=\left(\begin{array}{c}l \\ B_{\theta}\end{array}\right) \theta^{B_{\theta}}(1-\theta)^{l-B_{\theta}}$ and $\phi(l ; j, \theta)=\sum_{j=\bar{D}}^{l}\left(\begin{array}{l}l \\ j\end{array}\right) \theta^{j}(1-\theta)^{l-j}$.

Let's now turn to the comparative statics. It is immediate to verify that $\alpha$, when positive, is always increasing in $u_{g}$, decreasing in $c$ and non-monotone in $\nu$. It is also immediate to verify that for any $L=2, \alpha$, when positive, is increasing in $\theta$ and decreasing in $\rho$. Hence, we only need to prove that for $L \geq 2: \alpha$ is increasing in $\bar{D}$ and increasing in $\theta$. For $L \geq 2$, if $\alpha$ is greater than 0 , it is:

$$
\alpha_{\{>0\}}=\frac{u_{g}}{c} \cdot \sum_{k=0}^{\bar{D}-1} \frac{\sum_{i=k}^{L-1}(L-i) \cdot p(i) \cdot \operatorname{Pr}\left(B_{\theta}=k \mid i\right)}{L-k}+\frac{u_{g}}{c} \cdot \frac{\sum_{i=\bar{D}}^{L-1}(L-i) \cdot p(i) \cdot \operatorname{Pr}\left(B_{\theta} \geq \bar{D} \mid i\right)}{(L-\bar{D})}
$$

1. The fraction of viewers is increasing in $\bar{D}$.

To show that (k) is increasing in $\bar{D}$, let us consider a shift from $\bar{D}=H$ to $\bar{D}^{\prime}=H+1$, whereby $\alpha_{\{>0\}}$ will increase if

$$
\begin{aligned}
\frac{L-\sum_{i=H}^{L} i \cdot p(i) \frac{\operatorname{Pr}\left(B_{\theta}=H \mid i\right)}{\operatorname{Pr}\left(B_{\theta}=H\right)}}{L-H} & \geq \frac{L-\sum_{i=H}^{L} i \cdot p(i) \frac{\operatorname{Pr}\left(B_{\theta} \geq H \mid i\right)}{\operatorname{Pr}\left(B_{\theta} \geq H\right)}}{L-H} \\
\sum_{i=H}^{L} i \cdot p(i) \frac{\operatorname{Pr}\left(B_{\theta}=H \mid i\right)}{\operatorname{Pr}\left(B_{\theta}=H\right)} & \leq \sum_{i=H}^{L} i \cdot p(i) \frac{\operatorname{Pr}\left(B_{\theta} \geq H \mid i\right)}{\operatorname{Pr}\left(B_{\theta} \geq H\right)}
\end{aligned}
$$

To show that this inequality must hold, note that the right hand side equals

$$
\sum_{i=H}^{L} i \cdot p(i) \frac{\operatorname{Pr}\left(B_{\theta} \geq H \mid i\right)}{\operatorname{Pr}\left(B_{\theta} \geq H\right)}=\frac{\overbrace{\sum_{i=H}^{L} i \cdot p(i) \operatorname{Pr}\left(B_{\theta}=H \mid i\right)}^{\sum_{\sum_{i=H^{\prime}}^{L} i \cdot p(i) \operatorname{Pr}\left(B_{\theta} \geq H^{\prime} \mid i\right)}}}{\underbrace{\operatorname{Pr}\left(B_{\theta}=H\right)}_{\equiv B}+\underbrace{\operatorname{Pr}\left(B_{\theta} \geq H^{\prime}\right)}_{\equiv b}}
$$

and therefore, since $\frac{A+a}{B+b} \leq \frac{a}{b}$, it must be that

$$
\frac{A}{B} \leq \frac{A+a}{B+b}
$$


which completes the proof.

2. The fraction of viewers is non-decreasing in $\theta$.

As a first step, it is obvious that $\alpha$, when positive, is increasing in $\theta$ given $\bar{D}$. However, the reporting strategy of the media could change with an improved ability to gather bad signals. Here we show that $\bar{D}$ is increasing in $\theta$ as well. Finally, because $\alpha_{>0}$ is increasing in $\bar{D}$ as well, we obtain the result of interest.

Note that, at the margin between $\bar{D}=H$ and $\bar{D}^{\prime}=H+1$, we have:

$$
\begin{array}{r}
\sum_{i=H}^{L}\left(L-i-\frac{(L-H)}{u_{g}}\right) p(i) \operatorname{Pr}\left(B_{\theta} \geq H \mid i\right)=0 \\
\sum_{i=H}^{L}\left(\frac{L\left(u_{g}-1\right)-H}{u_{g}}-i\right) \cdot p(i) \cdot \operatorname{Pr}\left(B_{\theta} \geq H \mid i\right)=0
\end{array}
$$

Moreover, because $\operatorname{Pr}\left(B_{\theta} \geq H \mid i\right)$ is increasing in $\theta$ and faster for higher values of $i$, an increase in $\theta$ will put more weight on the positive values of the right hand side of the equation, i.e., $i>\frac{L\left(u_{g}-1\right)-H}{u_{g}}$. But then, for the equation to hold, it must be reduced the number of positive terms in the summation, i.e., $\bar{D}=H$ should move to $\bar{D}^{\prime}=H+1$. Q.E.D.

\section{Proof of Lemma 2}

Recall that over $L$ products, if the equilibrium threshold in the number of bad signals disclosed is $\bar{D}_{L}$, then it must be true that:

$$
u_{g} \cdot \sum_{i=\bar{D}_{L}}^{L}(L-i) p(i) \cdot \operatorname{Pr}\left(B_{\theta} \geq \bar{D}_{L} \mid i\right) \geq\left(L-\bar{D}_{L}\right) \sum_{i=\bar{D}_{L}}^{L} p(i) \cdot \operatorname{Pr}\left(B_{\theta} \geq \bar{D}_{L} \mid i\right)
$$

and

$$
u_{g} \underbrace{\sum_{i=\bar{D}_{L}+1}^{L}(L-i) p(i) \operatorname{Pr}\left(\bar{D}_{L}+1 \mid i\right)}_{\equiv A}<\left(L-\bar{D}_{L}-1\right) \underbrace{\sum_{i=\bar{D}_{L}+1}^{L} p(i) \operatorname{Pr}\left(\bar{D}_{L}+1 \mid i\right)}_{\equiv B}
$$

Note that the above conditions imply

$$
\begin{gathered}
u_{g} \underbrace{\sum_{i=\bar{D}_{L}}^{L}(L-i) p(i) \cdot \operatorname{Pr}\left(B_{\theta}=\bar{D}_{L} \mid i\right)}_{\equiv a}+u_{g} \underbrace{\sum_{i=\bar{D}_{L}+1}^{L}(L-i) p(i) \cdot \operatorname{Pr}\left(B_{\theta} \geq \bar{D}_{L}+1 \mid i\right)}_{\equiv A} \geq \\
\left(L-\bar{D}_{L}\right)[\underbrace{\sum_{i=\bar{D}_{L}}^{L} p(i) \cdot \operatorname{Pr}\left(B_{\theta}=\bar{D}_{L} \mid i\right)}_{\equiv b}+\underbrace{\sum_{i=\bar{D}_{L}+1}^{L} p(i) \cdot \operatorname{Pr}\left(B_{\theta} \geq \bar{D}_{L}+1 \mid i\right)}_{\equiv B}]
\end{gathered}
$$

By rearranging and combining the two, we obtain:

$$
u_{g} \cdot \frac{A+a}{B+b} \geq\left(L-\bar{D}_{L}\right)>1+u_{g} \cdot \frac{A}{B}
$$

Then, if we extend to the distribution $\mathcal{P}^{\prime}$, the measure of accuracy increases, i.e., $\varphi(L+1) \geq$ 
$\varphi(L)$, if and only if the new threshold $\bar{D}_{L+1} \geq \bar{D}_{L}+1$. Hence, it must be that

$$
u_{g} \cdot \sum_{i=\bar{D}_{L}}^{L+1}(L+1-i) p^{\prime}(i) \cdot \operatorname{Pr}\left(B_{\theta} \geq \bar{D}_{L}+1 \mid i\right) \geq\left(L-\bar{D}_{L}\right) \sum_{i=\bar{D}_{L}}^{L+1} p^{\prime}(i) \cdot \operatorname{Pr}\left(B_{\theta} \geq \bar{D}_{L}+1 \mid i\right)
$$

At this point, we can rewrite the l.h.s. of (p) as follows:

$$
\begin{aligned}
& u_{g} \nu \underbrace{\sum_{\bar{D}_{L}+1}^{L}(L-i) p(i) \operatorname{Pr}\left(\bar{D}_{L}+1 \mid i\right)}_{\equiv A}+u_{g} \nu \underbrace{\sum_{\bar{D}_{L}+1}^{L} p(i) \operatorname{Pr}\left(\bar{D}_{L}+1 \mid i\right)}_{\equiv B}+ \\
& +(1-\nu) \theta \cdot u_{g} \underbrace{\sum_{\bar{D}_{L}}^{L}(L-i) p(i) \operatorname{Pr}\left(\bar{D}_{L} \mid i\right)}_{\equiv a+A}+(1-\nu)(1-\theta) \cdot u_{g} \underbrace{\sum_{\bar{D}_{L}+1}^{L}(L-i) p(i) \operatorname{Pr}\left(\bar{D}_{L}+1 \mid i\right)}_{\equiv A}
\end{aligned}
$$

whereas the r.h.s. becomes:

$$
\begin{aligned}
& \left(L-\bar{D}_{L}\right) \nu \underbrace{\sum_{\bar{D}_{L}+1}^{L} p(i) \operatorname{Pr}\left(\bar{D}_{L}+1 \mid i\right)}_{\equiv B}+\left(L-\bar{D}_{L}\right)(1-\nu) \theta \underbrace{\sum_{\bar{D}_{L}}^{L} p(i) \operatorname{Pr}\left(\bar{D}_{L} \mid i\right)}_{\equiv b+B}+ \\
& +\left(L-\bar{D}_{L}\right)(1-\nu)(1-\theta) \underbrace{\sum_{\bar{D}_{L}+1}^{L} p(i) \operatorname{Pr}\left(\bar{D}_{L}+1 \mid i\right)}_{\equiv B}
\end{aligned}
$$

By using again condition (o), we obtain equation (??). Q.E.D.

\section{Proof of Lemma 3}

As shown in Proposition 2, when the media outlet observes $B_{\theta}=L$, it will always earn $\Gamma=\alpha$. This is clearly the upper-bound of the maximum profits that the media outlet may extract from producers. Hence, there is no loss of generality in in assuming that the all firms observe $\mathbf{z}$ (or equivalently, the media outlet discloses $\mathbf{z}$ to all firms). Suppose instead that $B_{\theta}<L$. Let's suppose that in this case the media outlet decides to not disclose $z_{l_{i}}$ to a subset of firms. Let's consider first the case where products are i.i.d. Since each firm knows the signal on its own product, i.e., each knows whether there are bad news about its own product or not, if a "good" firm rejects any possible contract offered by the media outlet, it will always end up earning at least $\alpha / L$. Therefore, regardless of which signals it decides to disclose to firms, the maximum ads fee that a media outlet may ask to a "good" firm will be $\tau$ (in exchange for revealing $D$ bad signals) such that:

$$
\Pi(D)-\tau \geq \alpha / L
$$

This implies that the media outlet may earn at most:

$$
\Gamma \leq \alpha-\left(L-B_{\theta}\right) \frac{\alpha}{L}=\frac{B_{\theta}}{L} \alpha
$$

which corresponds exactly to the media outlet's profits in the case where the media outlet and all firms observe $\mathbf{z}$. Hence again, there is no loss of generality in assuming that the all firms observe $\mathbf{z}$ (or equivalently, the media outlet discloses $\mathbf{z}$ to all firms). Let's now generalize the above reasoning to the correlated case. If products are correlated, it might be the case that, depending upon the degree of correlation, the media outlet may want to hide information about 
the actual number of "bad" firms to induce "good" firms to pay higher ads fees. Specifically, in principle, the media outlet may threaten good firms to reveal $B_{\theta}>\bar{D}$ if they do not pay an ads fee higher than, for example, $\alpha / L$. That is, they may threaten good firms to reveal enough bad news to induce informed consumers to not buy any product. However, this is clearly a non-credible threat. Indeed, as long as the media outlet may renegotiate its contracts before sending a message to its viewers, it will never have an incentive to make such a report since it will always better off by renegotiating the contract and reveal only $\bar{D}$ bad signals. Hence, "good" firms anticipate this and thus they will always reject any contract not satisfying ((q)). Therefore, the upper bound on the profits that the media outlet may earn by hiding a set of bad signals to producers is always equivalent to the equilibrium profits earned by the media outlet under our assumption that the all firms observe $\mathbf{z}$ (or equivalently, the media outlet discloses $\mathbf{z}$ to all firms).

Q.E.D.

\section{Proof of Proposition 4}

By paying the opportunity cost of accessing information, every media viewer has access to the same vector of messages about products' quality, i.e. $\mathbf{m}_{n_{i}} \equiv \mathbf{m} \forall n_{i}$. Obviously, for $\rho>\bar{\rho}$ (where $\bar{\rho}$ is defined as in (4)), no media outlet will ever be paid by an advertiser to disclose any negative information. That is, for any $\alpha>0$, both media outlets will be paid by (at least) one of the firm to hide any negative information. In turn, this implies that the media outlets' reports will never be informative. Hence $\alpha=0$. Let's now analyze the case where $\rho \leq \bar{\rho}$. First, suppose that $B_{\theta}=1$. That is, $z_{l_{1}}=b, z_{l_{2}}=\varnothing$. In order to avoid having informed consumers becoming informed of its bad quality product, $l_{1}$ has to pay a positive ads fee to both media outlets. Moreover, the maximum profits that firm $l_{1}$ may earn in the $\alpha$ marketshare of informed consumers is $\alpha / 2$ (since $l_{1}$ has to compete with the "good" quality firm $l_{2}$ ). Hence, from the media outlets' perspective, the most profitable contract that may offer to $l_{1}$

is $\left(t_{l_{1}}^{n_{i}}=\frac{\alpha}{4} ; \mathbf{m}_{n_{i}}=(\varnothing, \varnothing)\right), \forall i=1,2$. On the other hand, $l_{2}$ does not need to pay both media outlets to disclose $z_{l_{1}}=b$. Hence, each media outlet competes with the other to be the one paid by $l_{2}$ to disclose $z_{l_{1}}=b$. That is, by assuming that the two media outlets compete $a$ la Bertrand in the ads fees asked to $l_{2}$, the will end up both offering to firm $l_{2}$ a contract $\left(t_{l_{1}}^{n_{i}}=\frac{\alpha}{4} ; \mathbf{m}_{n_{i}}=(b, \varnothing)\right), \forall i=1,2$ (i.e., asking an ads fee equal to the maximum that $l_{1}$ would be willing to pay to each of them). Thus, $l_{2}$ will accept this offer from one of the media outlets who will then earn $\Gamma_{n_{i}}=\frac{\alpha}{4}$ (since given our tie-breaking rule, this media outlet prefers to be paid by the "good" firm and disclose the signal rather than being paid by the "bad" firm and hide it). Hence, the other media outlet will end up not earning anything since firm $l_{1}$ anticipates that all informed consumers will anyway observe $m_{l_{1}}=b$. Thus, given the tie-breaking rule, this media outlet will disclose the bad signal on firm $l_{1}$ as well. That is, $D_{n_{1}}=D_{n_{2}}=1$. Now, let's focus on the case where $B_{\theta}=2$. That is, $z_{l_{1}}=z_{l_{2}}=b$. Clearly, the two media outlets revealing different signals cannot be an equilibrium since both firms won't be willing to pay any ads fee in this case. Instead, if the two media outlets either conceal all signals or reveal the same bad signal while hiding the other, they would each earn half of the profits in the $\alpha$-market of informed consumers. Again, using the tie-breaking rule, the two media outlet will both prefer to hide the same bad signal and reveal the other one. That is, both media outlets earn $\Gamma_{n_{i}}=\frac{\alpha}{2}, \forall i=1,2$ from the firm whose signal has been concealed (and zero from the other one). That is, $D_{n_{1}}=D_{n_{2}}=1$. Q.E.D. 